\title{
The Rational and the Reasonable: Social Choice Theory and Adjudication
}

\author{
Bruce Chapman $\dagger$
}

It is odd that the economic theory of rational choice has so little to say about the role of reasoning in rational decision making. ${ }^{1}$ At a minimum, one would expect that the distinguishing feature of rational choice would be that it involves reasoning. A choice without a reason seems arbitrary, the very opposite of what rational choice would require.

However, the rational choice theorist will likely reply that rational choice involves reason in at least two respects. First, there is the idea of "dominance": a rational person should never (or does never) choose anything that she values less than other available alternatives. Second, there is "consistency": having already chosen in a particular way, a rational chooser should (or does) ${ }^{2}$ continue to

$\dagger$ Associate Professor, Faculty of Law, University of Toronto. I wish to thank, without implicating, Ian Ayres, David Beatty, Alan Brudner, Jules Coleman, Dick Craswell, Ron Daniels, Dan Farber, Robert Howse, Lewis Kornhauser, Brian Langille, Richard Posner, Susan Rose-Ackerman, David Schmidtz, Hamish Stewart, Cass Sunstein, Michael Trebilcock, George Triantis, Ernest Weinrib, and various participants at the second annual meeting of the American Law and Economics Association (Yale Law School, April 1992) for their comments on earlier versions of the arguments presented here. I am also very grateful to the Yale Law School for providing me with the opportunity to work on this Article by way of a 1991-92 Visiting Faculty Fellowship funded by the John M. Olin Foundation. Research funding from the Social Sciences and Humanities Research Council of Canada is also gratefully acknowledged.

This Article borrows its title from Chaï Perelman, The Rational and the Reasonable, in Perelman, The New Rhetoric and the Humanities: Essays on Rhetoric and Its Applications 117 (Reidel, 1979). This Article pursues some of the implications for the economic theory of rational social choice of the distinction, noted by Perelman, between what is reasonable in law and what is rational in deduction. See note 66.

1 For observations that this is a true characterization of rational choice theory, see Paul Anand, The Nature of Rational Choice and The Foundations of Statistics, 43 Oxford Econ Papers 199, 210 (1991); Amartya K. Sen, Rationality and Uncertainty, 18 Theory and Decision 109, 110-11 (1985).

2 These parenthetic phrases point to the equivocal nature of rationality. Rationality theory is sometimes descriptive, explaining why rational people behaved as they did or predicting how they will behave. At other times, it is prescriptive, suggesting how rational people ought to behave in the name of consistency or self-interest. There is increasing evidence from the psychological literature that rational choice theory confronts systematic failings as a descriptive theory. See generally Robin M. Hogarth and Melvin W. Reder, eds, Rational Choice (Chicago, 1987). For some suggestion that one may always characterize the choice 
choose in a way that does not contradict her earlier choices. I shall have a great deal more to say about dominance and consistency in the course of this Article, but for the moment it is enough to observe that, while dominance and consistency are certainly relevant to the rationality of decision making and choice, they do not give a complete account of reasoning. Reasoning also involves our capacities for thought and judgment, and concerns the justifications we offer for our choices. These things are largely unanalyzed in the merely consistent pursuit of undominated alternatives.

The relative indifference that rational choice theory shows toward reasoning is also apparent in the sorts of social institutions that social choice theorists study. Social choice theory, as the opening sentence of Kenneth Arrow's influential book Social Choice and Individual Values makes clear, ${ }^{3}$ is concerned with political voting and market transacting. But in neither of these social institutions does reasoning play an essential justificatory role. In politics, for example, while the final vote may be preceded by much discussion and exchange of reasons, the authority of the vote is not

problem in a way that makes apparently irrational behavior rational, see Paul Anand, Interpreting Axiomatic (Decision) Theory, 23 Annals of Operations Research 91 (1990).

${ }^{3}$ In a capitalist democracy there are essentially two methods by which social choices can be made: voting, typically used to make "political" decisions, and the market mechanism, typically used to make "economic" decisions.

Kenneth J. Arrow, Social Choice and Individual Values 1 (Yale, 2d ed 1963). Arrow's book has generated a huge literature, and social choice theory even has its own journal, Social Choice and Welfare. For excellent surveys of some of the results of social choice theory, see Amartya K. Sen, Collective Choice and Social Welfare (Holden-Day, 1970); Amartya Sen, Social Choice Theory, in Kenneth J. Arrow and Michael D. Intriligator, eds, 3 Handbook of Mathematical Economics 1073 (Elsevier Science, 1986); Dennis C. Mueller, Public Choice II 373-441 (Cambridge, 1989); Charles R. Plott, Axiomatic Social Choice Theory: An Overview and Interpretation, 20 Am J Pol Sci 511-596 (1976); and Thomas Schwartz, The Logic of Collective Choice (Columbia, 1986). For an interesting reconsideration of the fundamental assumptions underlying social choice theory, see generally Jon Elster and Aanund Hylland, eds, Foundations of Social Choice Theory (Cambridge, 1986). For criticism of social choice theory's approach to politics, see generally Richard H. Pildes and Elizabeth S. Anderson, Slinging Arrows at Democracy: Social Choice Theory, Value Pluralism, and Democratic Politics, 90 Colum L Rev 2121 (1990).

Social choice theory has yet to make much impact on legal theory. For examples of early attempts to apply social choice theory to legal problems, see Michael E. Levine and Charles R. Plott, Agenda Influence and its Implications, 63 Va L Rev 561 (1977); Mathew L. Spitzer, Multicriteria Choice Processes: An Application of Public Choice Theory to Bakke, the FCC, and the Courts, 88 Yale L J 717 (1979); Frank H. Easterbrook, Ways of Criticizing the Court, 95 Harv L Rev 802 (1982); and the pieces appearing in Symposium: The Implications of Social Choice Theory for Legal Decisionmaking, 9 Hofstra L Rev 13731484 (1981), and The Social Choice Perspective: A Second Look, 10 Hofstra L Rev 401-81 (1982). Daniel A. Farber and Philip P. Frickey, Law and Public Choice (Chicago, 1991), is a more recent book-length offering that emphasizes the positive (or predictive) uses as much as the normative uses of social choice theory. 
affected by the quality of this discussion. Such discussion need not even have occurred at all. And in market transacting, so long as one has the property right in question, one need not justify, or defend with reasons, one's willingness or reluctance to trade. What makes a political vote or a market transaction ultimately authoritative is simply the fact that those different acts of choosing have occurred, not the cogency of the reasoning involved.4

It would appear that judicial law making or adjudication is significantly different in this respect. Articulating reasons plays a much more essential role in legitimizing a judicial decision. It matters, of course, that a court, and particularly an appellate court, is the source of the decision in question. ${ }^{6}$ The opinion of an ordinary observer would have no authority at all over the parties in dispute, no matter how good the observer's reasoning. But the legal decision is meant to be more than just an administrative decision about some particular case. Rather, the judgment of an appellate court is typically stated in general terms, and its authority is intended to extend beyond the confines of its own particular facts to other like cases. This more extended claim to authority will be significantly affected by the quality of the reasons provided in support. A decision that is not supported by good reasons may be ignored, distinguished into oblivion, or labelled as "bad law" and simply overruled, even if it is a decision from the highest court. Thus, the quality of the reasoning provided for a legal decision is decisive for its authority in a way that is largely irrelevant to the authority of market and political choices.

The distinction initially drawn between reasoning and rational choice, therefore, parallels a contrast between, on the one hand, the justificatory role played by reasoning in legal adjudication and, on the other, the absence of such a role in the voting and market

- See Arthur L. Stinchcombe, Reason and Rationality, in Karen Schweers Cook and Margaret Levi, eds, The Limits of Rationality 288-89 (Chicago, 1990).

"This is a version of the "sources thesis," legal positivism's genuine insight. The sources thesis holds that the "validity," "form," "source," or "pedigree" of a legal proposition, and not just its moral content alone, determines its authoritativeness. For a discussion, see Joseph Raz, The Authority of Law (Oxford, 1979), particularly chapter 3. Legal positivism's error is its exclusive emphasis on form independent of content. This is merely the converse of the error, commonly attributed to the natural lawyer, that, in an equally onesided fashion, makes moral content the touchstone for legality regardless of form. On the need to pay attention to the correlative nature of form and content for a coherent understanding of law, see Ernest J. Weinrib, The Intelligibility of The Rule of Law, in Allan C. Hutchinson and Patrick Monahan, eds, The Rule of Law: Ideal or Ideology 59 (Carswell, 1987); Ernest J. Weinrib, Legal Formalism: On the Immanent Rationality of Law, 97 Yale L J 949, 950-75 (1988). 
transactions conventionally studied by rational social choice theorists. Yet this may overstate the institutional contrast. For consider the nature of the reasons that are provided in support of a decision in judicial law making. Typically what matters most in legal reasoning is the relation of similarity or difference that the instant case has to some earlier decision or line of precedent. If the court finds the instant case similar to a case or set of cases that has already been decided in a particular way, then the court should decide the instant case in the same way unless there is a good reason for distinguishing it. This is what is meant by legal consistency, or the formal justice notion of "treating like cases alike," and this is what is required by the doctrine of stare decisis. In other words, the reasoning so much in evidence in adjudication is very often more formal than substantive. What matters for the instant case is simply the positing of these prior legal decisions and a relation of either similarity or difference that the instant case bears to them. Substantive reasons of policy, for example, which might have been available to decide the earlier legal decision one way, or which are available now for deciding the instant case in the same or even a quite different way, will play, if anything, only a very secondary role. ${ }^{6}$ Thus, a legal decision may in large part be authoritative only because it seems coherent with some earlier legal choice that is itself neither explained nor justified. ${ }^{7}$

This may suggest that the reason-providing practices of adjudication are much more like the consistency requirements of rational choice than I have made out. "Coherence" and "consis-

${ }^{6}$ For a detailed version of this argument (distinguishing adjudication from policy), see Ronald Dworkin, Taking Rights Seriously 81-130 (Harvard, 1977); Ronald Dworkin, Law's Empire 221-24, 243-44 (Belknap, 1986).

3 Joseph Raz recently remarked that coherence theory, particularly coherence theory of law, is "in vogue." Joseph Raz, The Relevance of Coherence, 72 BU L Rev 273 (1992). These theories probably owe their popularity in the law to the influence of Ronald Dworkin's theory of legal integrity. See generally Dworkin, Law's Empire. For other accounts of coherence in law, see S. L. Hurley, Natural Reasons ch 10-12 (Oxford, 1989); S. L. Hurley, Coherence, Hypothetical Cases, and Precedent, 10 Oxford J Legal Stud 221 (1990); Barbara Baum Levenbook, The Role of Coherence in Legal Reasoning, 3 L \& Phil 355 (1984); Neil MacCormick, Coherence in Legal Justification, in Aleksander Peczenik, Lars Lindahl, and Bert van Roermund, eds, Theory of Legal Science 235-51 (Reidel, 1984). For something similar, if not identical, to a coherence account of legal reasoning, see Cass Sunstein, Analogical Reasoning, 106 Harvard L Rev 741 (1993). Sunstein identifies "four different but overlapping features" as characteristic of analogical reasoning: (i) principled consistency, (ii) a focus on particulars, (iii) incompletely theorized judgments, and (iv) principles operating at a low or intermediate level of abstraction. Id at 746-48. These bear an uncanny resemblance to the features identified in this Article as belonging to the process of legal reasoning toward a set of like cases. I am very grateful to Professor Sunstein for introducing me to the obviously related literature on analogical reasoning. 
tency," after all, sound like very similar virtues. But there is a difference between consistency and coherence, at least if the former term is taken to mean little more than non-contradiction. At the most, consistency as non-contradiction is a necessary condition for coherence, but it is not sufficient. A religious proposition may not contradict, and so may be consistent with, some proposition in physics, but it is hardly coherent with it. The claims of physics and chemistry, on the other hand, might be highly coherent. ${ }^{8}$ The difference is that the coherence in the second case is a function of the fact that physics and chemistry are engaged in a common project, perhaps the project of cataloging the laws of natural science (the accuracy of this description is not all that important for the point). By contrast, a religious proposition and a proposition of physics may be consistent precisely because religion and physics are not so engaged and, therefore, cannot contradict one another.

Thus, coherence is something more than consistency as noncontradiction. But of what relevance, it might now be asked, is all this to consistency of choice? After all, it is the relation between choice consistency as modeled by the rational choice theorist and legal coherence as modeled by the theorist of legal reasoning that is at issue here, and different acts of choice, unlike different statements of propositions, cannot really contradict one another. ${ }^{\ominus}$ Rather, acts of choice can only be contradictory if, say, the choice of $x$ from the set $(x, y, z)$ and the choice of $y$ from the set $(x, y)$ entail, respectively, that $x$ is a better alternative than $y$ and that $y$ is a better alternative than $x$, and that these propositions together contradict some understanding we have of "better."

As it happens, and as will be shown in greater detail in the next section, rational choice theorists typically do think that these acts of choice entail these kinds of statements. That is what is

- See Aleksander Peczenik, On Law and Reason 158 (Kluwer Academic, 1989). Compare MacCormick, Coherence in Legal Justification at 235:

Coherence in reasoning is one important test of its soundness as reasoning. It is a test which is not fully satisfied by mere consistency, in the sense of an absence of selfcontradiction. What I say may be free of any internal inconsistency and yet fail to "hang together" or to "make sense" as a whole.

- For a discussion of this point's importance for the conventions of rational choice, see Amartya Sen, Internal Consistency of Choice, 61 Econometrica 495 (1993). For a suggestion that ethical consistency, or the consistency of our normative prescriptions for action, might be different from the sort of consistency we have in our beliefs about true descriptions of the world, see Bernard Williams, Problems of the Self ch 11, 12 (Cambridge, 1973). Williams believes that this issue is relevant to the credibility of ethical realism as a theory. Id at 20405 . 
meant by a "revealed preference" theory. ${ }^{10}$ Under this interpretation, rational choice consistency does implicate, and is implicated by, non-contradiction. This Article asks whether this revealed preference interpretation of rational choice is itself consistent with a coherence theory of legal reasoning. As we shall see, it is not. Legal reasoning is coherent in a way that contradicts the most basic consistency axioms of rational choice theory.

So much the worse, it might be said, for coherence accounts of legal reasoning. That would be the predictable response of the rational choice theorist. Moreover, the legal skeptic would add that there is no real surprise here; it has long been apparent, she will say, that the law is riddled with contradiction and can be manipulated toward any result according to the whims and forces of politics.

However, both of these responses are premature. While the reason-giving practices of common law adjudication do not conform to even the most minimal choice-consistency conditions of rational social choice theory, there is, nevertheless, something perfectly reasonable or coherent in what the law does. What in particular that "something" is will vary from context to context, and it can only be described in general here as the construction of a set of "like cases." Moreover, the reasons provided from case to case will, even within a set of like cases, often appear quite different, perhaps even contradictory. Hence, the legal skeptic. But this is because courts provide reasons in adjudication that are specific to the different issues raised by different feasible sets of alternative choices. More particularly, different legal precedents have, as a matter of contingent historical fact, set different agendas for rationalizing like cases. Private law adjudication is, quite self-consciously and unabashedly, therefore, subject to what social choice theorists have come to refer to as "agenda influence" or "path dependence,"11 a feature they claim is suspect within any theory of goal-directed rational choice.

${ }^{10}$ Revealed preference theory was pioneered in P. A. Samuelson, $A$ Note on the Pure Theory of Consumer's Behavior, 5 Economica 61 (1938). For an exposition and critical discussion of revealed preference theory, see Amartya K. Sen, Choice Functions and Revealed Preference, 38 Rev Econ Stud 307 (1971), reprinted in Amartya Sen, Choice, Welfare and Measurement 41 (Blackwell, 1982).

11 Path independence ensures that the social choice from a set of alternatives is determined by the intrinsic merit of the alternatives available for choice, and not by arbitrary manipulations of the agenda. For a discussion and formalization of the concept of path independence, see Charles R. Plott, Path Independence, Rationality, and Social Choice, 41 Econometrica 1075 (1973). See also text accompanying notes 52-54. 
This Article contends that the diversity of reasons chosen to rationalize different cases, while evidencing contradiction to the legal skeptic, and arbitrary path dependence to the rational choice theorist, actually manifests law's overall reasonableness. The Article is organized as follows: Section I outlines the conventions of rational social choice that are relevant to this Article in both their preference-theoretic and choice-theoretic forms. This Section also suggests a structural interpretation of these rationality requirements in terms of the general theory of the good as contrasted with the theory of the right. Section II uses a simple abstract example to describe the very different notion of rationality inherent in legal reasoning. This form of reasoning is described variously as "formal justice" or "coherence" reasoning, or, in contrast to vertically deductive reasoning, as "horizontally analogous" reasoning. However described, this form of reasoning emphasizes the different relations between, rather than the comparable properties of, the various alternatives available. This feature of legal reasoning is what explains the path dependence of judicial law making: the final legal result depends on the sequence of choice. Legal reasoning is thus closer to theories of the right, with their emphasis on process, than to theories of the good, with their emphasis on the goals to be achieved in different end states. Section III illustrates the reasonableness of adjudication more concretely with an example from tort law. The illustration closely follows the structure of the abstract example used in Section II.

This Article suggests that not all agenda influences are arbitrary and, therefore, that path independence is not always a desirable property for social choice. Certainly, it does not seem to be a property of judicial law making. For agreement on this last point, see Lewis $A$. Kornhauser, Modeling Collegial Courts I: Path-Dependence, 12 Int Rev L \& Econ 169 (1992); Lewis A. Kornhauser and Lawrence G. Sager, Unpacking the Court, 96 Yale L J 82, 107 (1986).

Kornhauser's analysis of path dependence in judicial law making differs from that offered in this Article, however. First, Kornhauser argues that while judicial law making is not path independent, it is acyclical. Kornhauser, 12 Int Rev L \& Econ at 180-82. Here, I show that judicial law making is both path dependent and cyclical. The difference turns on the scope of judicial law making; while Kornhauser deems judges to be bound only by prior case results, id at 175-80, I argue that prior cases are also binding by virtue of their more general reasoning (although not by virtue of any particular reason, see text accompanying notes 63 83). Second, Kornhauser suggests that cycling can only occur if individual judges reveal in their choices an irrationality of the sort ruled out by the conventional assumptions of choice consistency in economics (such as in the weak axiom of revealed preference). Kornhauser, 12 Int Rev L \& Econ at 178. However, these choice-consistency requirements are, as general conditions on rational choice, as suspect as path dependence, and for much the same reason. See text accompanying notes $40-61$. 
Section IV addresses some nagging questions: What could be the advantage of constructing further "like cases" out of some precedent that just happens to arise given the "concrete history of the law"? ${ }^{12}$ Is it not paradigmatically irrational behavior to blindly repeat the past in this way? Why not try to do better if better alternatives are available ? $^{13}$ The last question, of course, is just that of the rational choice theorist, voicing her concern that superior alternatives not be ignored, but Section IV suggests why there might be some advantage, even for what rational choice theorists hope to achieve in social choice, in law's reasonableness. That advantage comes out of realizing that the real promise adjudication holds for achieving any goal, including a goal like efficient resource allocation, might come not from the self-conscious pursuit of that goal, but rather from fostering coordination across different persons' activities through the adjudication of a historically conditioned set of "like cases." Section IV illustrates this point by arguing that the judicial "mimicking" of efficient markets as prescribed, for example, by Judge Richard Posner within his theory of wealth maximization, ${ }^{14}$ may well be self-defeating. There is too much flexibility for the accommodation of a variable future in Posner's approach to wealth maximization, and too little fidelity to the past. Indeed, this Article will suggest that the most significant lesson to be derived from the generally negative results characterizing the forward-looking theory of rational social choice is that convention and tradition have a stabilizing role to play that has yet to be recognized by rational choice theorists in the same way it has been recognized in law.

$12 \mathrm{Raz}, 72 \mathrm{BU} L \mathrm{Rev}$ at 313 (cited in note 7 ).

${ }^{13}$ Frederick Schauer poses these questions in a self-critical way in two articles: Precedent, 39 Stan L Rev 571, 595-602 (1987), and Formalism, 97 Yale L J 509, 538-544 (1988). Schauer's emphasis on the importance of stability, while not exactly the same as this Article's emphasis on social coordination (see Section IV), involves related ideas.

14 This approach is advanced throughout Richard A. Posner, Economic Analysis of Law (Little, Brown, 4th ed 1992). See also William M. Landes and Richard A. Posner, The Economic Structure of Tort Law 1 (Harvard, 1987) ("This book explores the hypothesis that the common law of torts is best explained as if the judges . . . were trying to promote efficient resource allocation."). Landes and Posner define efficiency as Kaldor-Hicks efficiency or wealth maximization. Id at 16. See also Steven Shavell, Economic Analysis of Accident Law 3 (Harvard, 1987) ("If, for example, the social goal is the minimization of the sum of accident losses and the costs of accident prevention, one legal rule would be said to be better than another if it resulted in a lower sum of accident losses plus prevention costs."). With the notion of costs properly interpreted as opportunity costs, Shavell's cost minimization norm is equivalent to wealth maximization. 


\section{Rationality in the Theory of Social Choice}

In the economic theory of social choice, the social choice problem is typically set up in the following way. ${ }^{16}$ The objects of choice are elements of the set $\mathrm{X}$ of conceivable alternative social states. Social states should be thought of as complete and, therefore, mutually exclusive descriptions of the world, each varying from another in some normatively relevant particular capable of being altered by an act of choice.

This very broad definition of the objects of choice gives social choice theory its apparent generality. In political versions of the social choice problem, for example, the different social states will be defined according to which of several candidates is elected (Republican, Democratic, or Independent, for example), or which of several public policies or public goods is chosen (for example, the building of an electrical power plant at some particular location), with all other features of the social state held constant. But in more market-oriented interpretations of the social choice problem, "a social state would be a complete description of the amount of each type of commodity in the hands of each individual, the amount of labor to be supplied by each individual, [and] the amount of each productive resource invested in each type of productive activity ...."16 Where social choices between political candidates will usually be determined by voting, social choices on market matters, such as how much labor to supply, will more likely be determined, as a matter of personal choice, by the individuals concerned. But market choices between different social states involving different levels of work effort are no less social because they are left to individuals, at least within the conventions of social choice theory. ${ }^{17}$ Indeed, it is this feature that embeds certain liberal value judgments within social choice and, therefore, that use-

${ }_{13}$ See, for example, Sen, Collective Choice 1-70 (cited in note 3).

16 Arrow, Social Choice at 17 (cited in note 3).

17 See id at 18. In Arrow's view, the partitioning of social action into domains of individual action and choice is, literally, an outcome of some prior "social policy."

The fundamental fact which causes the need for discussing public values at all is that all significant actions involve joint participation of many individuals. Even the apparently simplest act of individual decision involves the participation of a whole society.

... It is quite customary to think of each individual as being able to undertake actions on his own (e.g., decisions of consumption, production, and exchange, moving from place to place, forming and dissolving families)... . [A]ny social action is thought of as being factored into a sequence of individual actions.

I certainly do not want to deny that such factoring takes place, but I do wish to emphasize that the partition of a social action into individual components, and the corresponding assignment of individual responsibility, is not a datum. Rather, the par- 
fully allows the theory to test those judgments for their consistency with other ethical and social choice criteria. Amartya Sen's important and much discussed theorem on "the impossibility of the Paretian liberal" is just one well-known example. ${ }^{18}$

In legal reasoning, the alternative social states can plausibly be interpreted as judicial choices among the alternative legal rules, principles, or rationales that might be available to govern a case, or set of cases, holding all other defining features of the social states constant. This interpretation is consistent with that provided by Judge (then Professor) Frank Easterbrook, one of the first to bring social choice theory to bear on the analysis of legal decision making. ${ }^{19}$ Judge Easterbrook considered as an example a case involving the Establishment Clause of the First Amendment and identified. three possible judicial positions, each articulating a different rule to govern the relevant cases. ${ }^{20}$ Under this interpretation, each judge or panel of judges constantly adjusts the rule or, equiva-

ticular factoring in any given context is itself the result of a social policy and therefore already the outcome of earlier and logically more primitive social values.

In economic transactions the point is clearest when we consider what we call property. Property is clearly a creation of society through its legal structure. The actions of buying and selling through offers of property are only at a superficial level the actions of an individual. They reflect a whole series of social institutions, and with different institutions different people would be having control over any given piece of property. Furthermore, the very notion of control over one's "own" property, as is apparent upon the most casual inspection, itself acquires its meaning through the regulations of society.

K. J. Arrow, Values and Collective Decision-Making, in Edmund S. Phelps, ed, Economic Justice 117, 121-22 (Penguin, 1973).

We need not accept this claim (at least without more argument). But even if we recognize the claims of individual right as prior to social policy, we can still admit that it is important to investigate those claims within the overall context of social choice so that their social implications can be better understood. The view that individual rights are merely the product of logically prior social policy decisions and, as some libertarians might claim, cannot provide ex ante constraints on social decision making, is, of course, a large part of the message delivered first by legal realism and later by critical legal studies. See generally Robert L. Hale, Bargaining, Duress, and Economic Liberty, 43 Colum L Rev 603 (1943); Robert L. Hale, Coercion and Distribution in a Supposedly Non-Coercive State, 38 Pol Sci Q 470 (1923). See also Joseph William Singer, The Legal Rights Debate in Analytical Jurisprudence from Bentham to Hohfeld, 1982 Wis L Rev 975, 1012-13, 1031-34, 1056-59.

${ }^{18}$ Amartya Sen, The Impossibility of a Paretian Liberal, 78 J Pol Econ 152 (1970). This theorem has spawned a huge commentary, some of it book-length. For a summary of, and reply to, some of it, see Amartya Sen, Liberty, Unanimity and Rights, 43 Economica 217 (1976). For more recent discussion, see Jonathan Riley, Liberal Utilitarianism ch 11 (Cambridge, 1988). The particular issue of how to embed liberal value judgments in social choice theory is discussed in Robert Nozick, Anarchy, State, and Utopia 164-66 (Basic Books, 1974), and Bruce Chapman, Rights as Constraints: Nozick Versus Sen, 15 Theory \& Decision 1 (1983).

19 Easterbrook, 95 Harv L Rev 802 (cited in note 3).

$20 \mathrm{Id}$ at 815. 
lently, chooses a new rule to meet the changing circumstances of each case. The law therefore develops in an "incremental" teractive"22 social choice process.

Returning to the general characterization of the social choice problem, it seems reasonable to assume that at any one time only a subset of X (the set of all conceivable social states) will actually be available for choice. Let $\mathrm{K}$ stand for the family of all possible nonempty subsets of X. Each element $S$ of $K$, therefore, contains the alternatives available for choice in some more particular choice situation. S might be thought of as the choice set or agenda or, more suggestively for the purposes of this Article, as defining the issue. A lively political issue could involve which of several possible locations should be chosen for a new airport, for example, and in a legal case the issue might be whether the rule on proximate cause in tort should be extended to include the plaintiff's injury. ${ }^{23} \mathrm{~A}$ social choice function $\mathrm{C}$ on the set $\mathrm{K}$ is a function that maps each $\mathrm{S}$ of $\mathrm{K}$ into a non-empty subset of $\mathrm{S}$, namely $\mathrm{C}(\mathrm{S}) . \mathrm{C}(\mathrm{S})$, therefore, is the set of chosen elements from the set $\mathrm{S}$. To summarize this general characterization of the social choice problem, then, we might say that $\mathrm{X}$ defines the conceivable options, a given $\mathrm{S}$ defines the practical issue, and $\mathrm{C}(\mathrm{S})$ defines the choice or resolution of that issue.

To move from $\mathrm{S}$ to $\mathrm{C}(\mathrm{S})$, choice criteria, which define the different social choice functions $\mathrm{C}$, are obviously required. Needless to say, this is where much of the work is done in social choice theory, especially since Kenneth Arrow first showed that seemingly weak, or benign, choice criteria can be incompatible. ${ }^{24}$ Moreover, since the choice criteria define what is "proper" in social choice, one would naturally expect that this would be an area of considerable controversy among social choice theorists. And that is so. $^{25}$ However, on the logical relationship that ought to exist between $\mathrm{S}$, $\mathrm{C}(\mathrm{S})$, and the choice criteria (whatever these might be), there is general agreement about how to proceed. ${ }^{26}$ Since this logical relationship goes to the heart of what it means to make a rational so-

${ }^{21}$ See Kornhauser, 12 Intl Rev L \& Econ at 171 (cited in note 11).

${ }^{22}$ See Riley, Liberal Utilitarianism at 261-62 (cited in note 18).

${ }^{23}$ This is the issue in the tort cases discussed in Section III.

24 Arrow, Social Choice at 51-59 (cited in note 3).

${ }^{25}$ See, for example, the debate on how one ought to formulate the value of liberty in the commentary on Sen's theorem cited in note 18.

${ }^{28}$ An early dissenter from this convention was Thomas Schwartz, Rationality and the Myth of the Maximum, 6 Noûs 97 (1972). See also Schwartz, Logic of Collective Choice at $1-2,125-31$ (cited in note 3 ). 
cial choice given any choice criteria, I will focus on this area of broad agreement.

Typically, the choice set $S$, the chosen elements $C(S)$, and the different choice criteria that define $\mathrm{C}$ are related in the following way: An alternative social state $x$ is in C(S) if and only if $x$ is available for choice; and for no alternative social state $y$, which is also available, is it true that $y$ is socially preferred to $x$ according to the relevant choice criteria. In symbols, and denoting the relation "is socially preferred to" by the letter $\mathrm{P}$, this definition of a chosen element is written:

(1) $x \in \mathrm{C}(\mathrm{S})$ if and only if $x \in \mathrm{S}$ and for no $y \in \mathrm{S}, y \mathrm{P} x$.

In this way, therefore, the classical definition (1) of a chosen alternative formalizes the dominance idea that to choose rationally, given one's choice criteria, is to maximize, that is, to choose in such a way that no other choice would have been better, or socially preferable, according to these criteria. ${ }^{27}$ Maximization is, of course, a tempting idea, and one can understand why most social choice theorists have adopted it. Anything less seems to make a nonsense of having choice criteria at all, since it would involve choosing an alternative that the choice criteria themselves have identified as inferior.

Nevertheless, this Article challenges this notion of rational choice, at least as a way of modeling rationality in legal adjudication. This challenge to the rationality of the general maximization model also implies skepticism about more particular maximizing claims, for example, that the underlying rationale for the common law could (or should) be found in wealth maximization. However, while this Article questions the normative foundations for much of economic analysis of law, it also implicates any legal theory with the same general structure or orientation toward the rational choice of some good. ${ }^{28}$ To mount this challenge and ground its ar-

${ }^{27}$ Thus, maximization is closely related to the idea of dominance. See text accompanying note 2. For an explicit characterization of dominance as maximization, see Anand, 43 Oxford Econ Papers at 207 (cited in note 1).

${ }^{28}$ The economic analysis of law, while it chooses wealth as a particular and controversial maximand, merely exemplifies the more general maximizing structure of rational choice modeled by social choice theory. Thus, any challenge to the general structure of maximization amounts to a challenge against the more particular concern to maximize wealth. But one might still think that less controversial maximands than wealth would provide appropriate criteria for rational legal decision making. However, this Article questions whether the structure of maximization is general enough in form to accommodate what is reasonable in adjudication. 
gument against such theories more effectively, we need some further related characterizations of the rationality of social choice.

First, we need to say more about the above-mentioned social preference relation $\mathrm{P}$. Clearly, if this preference relation is cyclical over all the alternatives in some $\mathrm{S}$, then there is no $\mathrm{P}$-undominated (best, most preferred) alternative in $\mathrm{S}$ and, according to definition (1), C(S) must be empty. This is what Judge Easterbrook is getting at when he argues that it is inconsistent for a court to indicate, for example, "that freedom of speech is a more important constitutional value than a defendant's right to a fair trial, that fair trial is more important than military preparedness, and that military preparedness is more important than free speech."29 There is no direct contradiction here, as there would be if the same court had said in one case that a jury trial was a "valued right" and yet in another that it was "irrelevant." 30 Still, the cycle in the "more important than" relation makes it impossible to isolate what is most, or maximally, important. In turn, this makes it impossible to choose rationally, according to definition (1), from this set of three constitutional values.

Thus, to ensure the possibility of rational choice in all $\mathrm{S}$, the social preference relation defined by the choice criteria must satisfy the rationality condition acyclicity: For all (finite) sets of alternatives $\left(x_{1}, x_{2}, \ldots x_{t}\right)$ in $\mathrm{X}$, it is never the case that $x_{1} \mathrm{P} x_{2}$, $x_{2} \mathrm{P} x_{3}, \ldots x_{t-1} \mathrm{P} x_{t}, x_{t} \mathrm{P} x_{1}$. Acyclicity is the weakest member of a family of rationality requirements that are typically imposed on social preference relations in social choice theory. The strongest such rationality requirement, and the one originally required by Arrow in the proof of his famous theorem, is full transitivity of the social preference and indifference relation $\mathrm{R}$. Full transitivity requires that for all $x, y, z$ in $\mathrm{X}$, if $x \mathrm{R} y$ and $y \mathrm{R} z$, then $x \mathrm{R} z$, where $\mathrm{R}$

For substantive criticisms of wealth maximization as a normative concern for law, see generally Ronald M. Dworkin, Is Wealth a Value?, 9 J Legal Stud 191 (1980); Anthony T. Kronman, Wealth Maximization as a Normative Principle, 9 J Legal Stud 227 (1980); Jules L. Coleman, Efficiency, Utility, and Wealth Maximization, 8 Hofstra L Rev 509 (1980); and Ernest J. Weinrib, Utilitarianism, Economics, and Legal Theory, 30 U Toronto L J 307 (1980). Note that these criticisms focus on wealth as an inappropriate maximand, while this Article targets the more general idea of maximizing itself. For defenses of wealth maximization against these more particular criticisms, see Richard A. Posner, The Value of Wealth: A Comment on Dworkin and Kronman, 9 J Legal Stud 243 (1980); Richard A. Posner, The Ethical and Political Basis of the Efficiency Norm in Common Law Adjudication, 8 Hofstra L Rev 487 (1980); and D. Bruce Johnsen, Wealth is Value, $15 \mathrm{~J}$ Legal Stud 263 (1986).

${ }^{20}$ Easterbrook, 95 Harv L Rev at 811-12 (cited in note 3) ("To do so is to say that at least one decision is wrong or that they do not rest on the same document.").

${ }^{30}$ Id at 811. 
is read as "is socially preferred or indifferent to" or "is socially at least as good as." Obviously, if $x \mathrm{R} y$ is defined as not- $y \mathrm{P} x$ (and $\mathrm{R}$ is connected for all alternatives in $\mathrm{X}^{31}$ ), then full transitivity implies acyclicity. Thus, full transitivity also ensures that $\mathrm{C}(\mathrm{S})$ will be nonempty. The discussion to follow will focus more on full transitivity than on acyclicity; however, as some of the attention to choice-theoretic detail will make clear, this Article's reservations about full transitivity as an appropriate rationality requirement for legal decision making are equally applicable to weaker conditions such as acyclicity. ${ }^{32}$

At this point, an economist or rational choice theorist might object that all this talk of rationality requirements for the social preference relation is misleading if it suggests that the notion of social preference is somehow prior to, or independent of, social choice. As a behavioral scientist, the economist is certainly more at home with the idea that observed choices reveal preferences and, indeed, may wonder if preferences even need to be mentioned at all. ${ }^{33}$ However, the avowed behaviorist has her own set of consistency conditions to impose on observed choices, and it turns out that these consistency conditions are simply the choice-theoretic

31 The relation $\mathrm{R}$ is connected if for all $x$ and $y$ in $\mathrm{X}$, either $x \mathrm{R} y$ or $y \mathrm{R} x$, or both. This condition is not as innocuous as it might seem. For example, the possibility that preferences may be "disconnected" (or alternatives non-comparable) is the basis for Isaac Levi's reconstruction of rational choice under his theory of "unresolved conflict." See generally Isaac Levi, Hard Choices (Cambridge, 1986). For interesting discussions of the non-comparability of certain alternatives, see Joseph Raz, The Morality of Freedom (Oxford, 1986), especially chapter 13 on "Incommensurability"; James Griffin, Well-Being ch 5 (Oxford, 1986); T. K. Seung and Daniel Bonevac, Plural Values and Indeterminate Rankings, 102 Ethics 799 (1992); Michael Stocker, Plural and Conflicting Values (Oxford, 1990); and Amartya Sen, Plural Utility, 81 Proceedings of the Aristotelian Society 193 (1980-81).

${ }^{32}$ See text accompanying note 52.

${ }^{33}$ See, for example, John A. Ferejohn and Debra Satz, Rational Choice and Social Theory, Working Paper No 59, Center for Law and Economic Studies, Columbia University School of Law (Aug 25, 1991). Ferejohn and Satz claim that rational choice theory entails no particular psychological view that agents maximize preference satisfaction. Only choice consistency, or what they term "a coherence requirement on behavior," is assumed. Id at 6 . They then go on to define choice consistency in one of the conventional ways this Article discusses. (There is, actually, some charity in this interpretation of their definition since the choice-consistency conditions they invoke in note 6 of their manuscript are inadequate to support their definition of rational choice. It seems that they have inadvertently reversed the direction of a subset relation.) However, as Sen has effectively argued, there must be more to rationality than mere choice consistency. See Sen, 18 Theory and Decision at 110 (cited in note 1). After all, a person who chooses in a consistently opposite way to her preferences or values is no less consistent than someone who chooses more conventionally, but it would be hard to claim that her choices are just as rational. This is where the rational choice theorist's concern for dominance seems to have some relevance. 
analogues of the rationality requirements which the preference theorist would impose on preferences.

To see this, consider the most common of choice-consistency conditions imposed on observed choices, namely the weak axiom of revealed preference ("WARP"). ${ }^{34}$ WARP requires that if a person or institution reveals a preference for some alternative $x$ over some alternative $y$-meaning the person or institution chooses $x$ and rejects $y$ when both are available - then that same person or institution must not also reveal a preference for $y$ (choose $y$ ) over $x$ (reject $x$ ) in any other situation where both alternatives are available. One is tempted to say that this much follows, trivially, from simply having a preference, but that would be to forget that revealed preference theory purports to give preference only a derivative role, secondary to observed choices. The only claim that makes sense in exclusively choice-theoretic terms is the one which argues that it is inconsistent to choose $x$ over $y$ in one choice situation and $y$ over $x$ in another. This too is a seemingly trivial claim, and one that has at least a surface plausibility as an account of what might be meant by consistency (or, more particularly, non-contradiction) in the choice of legal rules.

Nevertheless, the temptation to account for WARP straightforwardly in terms of an unchanging preference is revealing in that it suggests that WARP is plausible, or even trivial, in large part because it is based on the belief that rational preferences motivate (and stand prior to) consistent choices. ${ }^{35}$ The fact that WARP is the logical equivalent, in choice-consistency terms, of full transitivity in a preference relation further supports this suggestion.

At first sight this last claim may appear surprising, since WARP would seem to have nothing to say about consistency of choice between more than two alternatives. But suppose that some person or institution has, in a series of pair-wise choices, revealed a preference for $x$ over $y$, for $y$ over $z$, and, in violation of transitivity, for $z$ over $x$. (Judge Easterbrook provides us with a ready court-focused example. ${ }^{36}$ ) While there is nothing in this so far to violate WARP (no direct contradiction of values), it would, nevertheless, now be impossible to make a choice from the set of alternatives $(x, y, z)$ without doing so. That is, any choice from this

${ }^{34}$ For a discussion, see the references cited in note 10.

${ }^{35}$ See Amartya K. Sen, Behavior and the Concept of Preference, 40 Economica 241, 242-44 (1973), reprinted in Amartya Sen, Choice, Welfare and Measurement 54, 55-57 (Blackwell, 1982).

${ }^{36}$ See text accompanying note 29 . 
triple would violate WARP given the earlier choices from the alternatives considered one pair at a time. In a sense, the inconsistency is simply lurking in the prior choices, waiting for a suitable opportunity to show itself. Thus, if one insists that consistent choice should always be possible (that $C(S)$ be non-empty for all sets $S$ in $\mathrm{K}$ of $\mathrm{X}$ ), then WARP will not only guarantee two-alternative consistency, but will also ensure against intransitivity and, therefore, preserve the possibility of maximization under definition (1) above. $^{37}$

In addition to this essentially preference-based argument for the plausibility of WARP as a choice-consistency condition, WARP also provides a reasonably general structure for understanding what it might mean to satisfy the formal justice injunction that "like cases should be treated alike." The like treatment of like cases is, after all, one of the most commonly articulated choice-consistency requirements in law, ${ }^{38}$ so common in fact that many are inclined to think it devoid of substance and thus incapable of doing any real work. ${ }^{39}$ The real work, it is suggested, can only be done when the criterion for "likeness" is identified. However, as the following analysis shows, WARP can be interpreted as providing a more particular interpretation of what it might mean to treat like cases alike without actually identifying any substantive criterion for "likeness."

Essentially, WARP requires that the inclination to choose an alternative $x$ over another alternative $y$ not be a function of what other alternatives might be available in the choice set $\mathrm{S}$. If $x$ is ever chosen over $y$, say, in the choice set $\mathrm{S}_{1}$, then $y$ can never be chosen over $x$ in another choice set $S_{2}$, no matter what alternatives are added to, or subtracted from, $\mathrm{S}_{1}$. Again, the merely structural

${ }^{37}$ See Sen, 40 Economica at 244-47 (cited in note 35).

38 See Kornhauser, 12 Intl Rev L \& Econ at 180 (cited in note 11) ("A system of adjudication must satisfy some 'consistency' requirements that include the injunction 'treat like cases alike' and that condemn 'cycling' among outcomes.").

${ }^{39}$ See generally Peter Westen, The Empty Idea of Equality, 95 Harv L Rev 537 (1982). For criticism of Westen's argument, see generally Kent Greenawalt, How Empty is the Idea of Equality?, 83 Colum L Rev 1167 (1983); and Steven J. Burton, Comment on "Empty Ideas": Logical Positivist Analyses of Equality and Rules, 91 Yale L J 1136 (1982). For a suggestion that this whole debate misses the more fundamental point that while an idea might be empty it can still determine its content (by excluding other content inappropriate to its form or structure), see Weinrib, 97 Yale L J at 981-82 n 72 (cited in note 5). Weinrib's emphasis on the importance of structure as determinative of content is comparable to this Article's claim that the structure of maximization in social choice theory is inconsistent with the structure of legal adjudication within a coherent set of like cases. This claim does not turn on any particular content (for example, some specific maximand or notion of "likeness"). 
aspect of WARP's characterization of "like cases" needs to be emphasized, since here too, just as for rational choice generally, there is no claim that any substantive criterion for choice, nor any particular criterion for the identification of like cases, need be advanced. The only claim is that the choice between any two fully specified, and unchanging, alternative social states $x$ and $y$ is a like case, and should be treated alike, regardless of what other alternative social states might be available in the choice sets. In this sense, WARP appears to provide an appropriately general account of what it should mean to treat like cases alike.

Nevertheless, we can now begin to see that there is a more particular kind of understanding of like cases at play in WARP. This understanding suggests that the general model of rational social choice may not be so very general after all. WARP makes sense as a choice-consistency condition for "like cases" only if choices are motivated by certain properties intrinsic to, or embedded in, the alternative social states. ${ }^{40}$ For example, we may be drawn toward choosing certain alternative social states because of the amount of wealth, happiness, equality, or love enjoyed by the individuals who live in those social states as compared to some others. Then, surely, we would expect our choices between two alternative social states, each characterized by only these intrinsically important properties, to be invariant with respect to the presence or absence of other alternatives in the various choice sets that might be constructed, just as WARP requires. ${ }^{41}$

10 Even so philosophically sensitive a theorist of rational choice as Paul Anand seems compelled to characterize the reasons for choice as properties of the alternatives to be chosen rather than, say, properties of the relations that might exist between those alternatives. See Anand, 43 Oxford Econ Papers at 210 (cited in note 1).

11 This may seem an especially reasonable consistency requirement once one recognizes that the alternatives for choice are (because they are so finely described) mutually exclusive social states, as they are in social choice theory. There is therefore no point in considering how the different alternatives might relate to one another. They never exist together as complementary alternatives; for example, the choice of one precludes the choice of the other.

Paul Samuelson made a similar argument for his "independence axiom," a closely related rationality requirement found in expected utility theory (the theory of rational choice that addresses situations involving risk). See Paul A. Samuelson, Probability, Utility, and the Independence Axiom, 20 Econometrica 670, 672-73 (1952). But, interestingly, criticisms of this independence axiom turn on the fact that choosers react to "non-separable" features of the lotteries they face, that is, features of the lottery as a whole rather than of any one of the possible social states taken separately. For example, this is the basis of the "certainty preference" in Allais's paradox. See Maurice Allais, The Foundations of a Positive Theory of Choice Involving Risk and a Criticism of the Postulates and Axioms of the American School, and The So-called Allais Paradox and Rational Decisions Under Uncertainty, both in Maurice Allais and Ole Hagen, eds, Expected Utility Analysis and the Allais Paradox 
However, reasonable social choice might also be influenced by the relations that exist between the different alternatives for choice. After all, the choice set $\mathrm{S}$ defines the issue for choice and, presumably, two different choice sets $S_{1}$ and $S_{2}$ will define two different issues. Should we expect the choice between alternative social states $x$ and $y$ always to be invariant with respect to changes in the issues, as WARP seems to require? Interpreted this way, the choice-consistency condition is a strong one indeed. Different issues, defined by different choice sets, might well call for different reasoning and, therefore, different choices, even over the same two alternative social states. ${ }^{42}$

An example may help to make the point more clear..$^{43}$ Suppose that one must choose which of three candidates $\mathrm{A}, \mathrm{B}$, or $\mathrm{C}$, should

27-145, 437-681 (Reidel, 1979). The certainty (attractive to some) of getting some given payoff in every possible state of nature (or social state) is not a property of any one state of nature; rather, it is a property of all the (mutually exclusive) social states considered as a whole.

12 This is the thrust of arguments recently advanced in Edward F. McClennen, Rationality and Dynamic Choice (Cambridge, 1990). McClennen mounts a thorough and convincing challenge against what he calls the "context-free choice condition," id at 23, a choiceconsistency requirement almost identical to WARP. As we have already observed, WARP abstracts from any influence that the "context" of options available for choice might otherwise provide. See also Paul Anand, The Philosophy of Intransitive Preference, 103 Econ J 337, 339 (1993):

[M] embers of the feasible set go to make up the context in which choice is exercised. Choices made from differing opportunity sets can have quite different meanings (gestalt) just as they might draw on very different forms of justification or explanation.

13 The following example is a variation on that found in James F. Reynolds and David C. Paris, The Concept of "Choice" and Arrow's Theorem, 89 Ethics 354, 363 (1979). Comparable examples, making very similar points, are developed in Levi, Hard Choices at 105 (cited in note 31); and Anand, 103 Econ $\mathrm{J}$ at 339, 344. Anand's second example clearly shows how different partitions of the alternatives raise different issues: You are about to be offered fruit at a dinner party. If offered a choice between a small apple and an orange, you would choose the orange. If offered the choice between a large apple and the orange you would choose the large apple. Yet, given a choice between the large and small apple, concerns about proper etiquette at a dinner party might induce you to choose the small apple. This is intransitive choice, but it hardly seems irrational. The problem is that etiquette only comes up as an "issue" in the last choice; the rule, "When confronted with a large and small $\mathrm{X}$, it is proper to choose the small one," simply has no purchase on the other choices, since a comparison between different sized X's is not at issue there.

The commonly made observation that tournaments of sports teams often do not reveal transitive orderings of their overall abilities can also be explained as a kind of issue dependence. For example, a baseball team with good fastball pitching might beat a team with good base stealing, and the team with good stealing might beat a team with good off-speed pitching. These matchups make "stealing" an issue, and while stealing is an advantage against off-speed pitching, it is hard to steal against fastballs. However, when the two pitching teams play, stealing may no longer be an issue between them, and it is quite possible that the off-speed team will beat the fastball team every time, the requirements of transitivity notwithstanding. 
receive a certain monetary award. As between $A$ and $B$, it is clear that $\mathrm{A}$ will do more good with the award, and so one is naturally inclined, all else being equal, to choose $\mathrm{A}$ in that situation. Similarly, as between B and C, it appears that B will do more good with the award than $C$. Thus, for comparable reasons, one is inclined in that situation to choose $B$. Does this mean that one would necessarily feel obliged to choose A were all three candidates available for choice? Not really. Choosing A over B in the first hypothetical did not mean choosing $\mathrm{A}$ over $\mathrm{C}$, which is implied by choosing $\mathrm{A}$ from the triple. This might make a lot of difference. Suppose, for example, that $\mathrm{A}$ owes $\mathrm{C}$ money; then there might be something disquieting in choosing to give even more money to $A$ in the presence of $C$, something that would not affect the choice between $A$ and $B$ at all. Thus, one might want to choose $A$ over $B$ when the choice set is $(A, B)$, and where the money debt between $A$ and $C$ is not an issue, yet choose $B$ over $A$ and $C$ when the choice set is $(A, B, C)$ and the money debt between $\mathrm{A}$ and $\mathrm{C}$ is an issue, the choice-consistency requirements of WARP notwithstanding. ${ }^{44}$ On the one hand, choosing $B$ rather than $C$ allows some greater good to be done with the award than would be done if $\mathrm{C}$ were chosen, while, on the other hand, not exacerbating the injustice characterizing the relation between A and C. Such an "issue dependent" approach to the choice between $\mathrm{A}$ and $\mathrm{B}$, although it may not capture the most sophisticated accounts of corrective justice now available, ${ }^{45}$ is, nevertheless, quite comprehensible. It seems wrong that WARP rules out this approach as an irrational choice-inconsistency from the start. ${ }^{46}$

14 Note that the same sort of reasoning would lead one to choose $C$ over $A$ in the choice from the pair (A,C). Combined with the choice of $A$ from the pair $(A, B)$, and $B$ from the pair $(B, C)$, we can see that the same sort of reasoning leads, quite plausibly, to a violation of the transitivity requirement for rational preferences.

is See generally Jules L. Coleman, Tort Law and the Demands of Corrective Justice, 67 Ind L J 349 (1992); Stephen R. Perry, The Moral Foundations of Tort Law, 77 Iowa L Rev 449 (1992); and Ernest J. Weinrib, Understanding Tort Law, 23 Valp U L Rev 485 (1989).

46 WARP might even rule out the possibility of accurately describing what is involved in a given choice. For an interesting example, see Amartya K. Sen, Freedom of Choice: Concept and Content, 32 European Econ Rev 269, 290-93 (1988). Someone may want to "fast," but fasting is more than just going without food. It has to be distinguished somehow from simply starving involuntarily. Not surprisingly, the distinction turns on what is available in the choice or opportunity set. We fast when we have the option not to go without food. Thus, we might choose "going without any food" when we have the options of "having more than enough food," and "having minimally adequate food," but might choose the third of these over the first when these are our only alternatives. More generally, acts of protest and denial might have this character. What matters in protest is what we choose in the face 
The issue-dependent choices just described do not depend on ascribing to corrective justice some kind of value that has a lexical priority over the competing value of achieving good with the reward. It is quite possible that at some point the concerns we have for the achievement of the greater good will trump the concerns we have for respecting corrective justice. It just so happens that we are not yet at that point in the example. (Perhaps the disparity in the good is not yet so large, or the past injustice in need of correction is still very recent.) Rather than think of these different values as "incomparable" in this way, so that the lexically superior one is always "incomparably better" (if that even makes sense), it is more accurate to say that the different values are "incommensurable." That is, there is no common metric for assessing what is important in all the different choices. The different alternatives in the different (albeit overlapping) choice sets generate different issues, some of which are present (and decisive) in some choice situations but totally absent in others. This may involve a kind of non-reductive plurality of the values at stake, but it need not imply that the values are non-comparable. ${ }^{47}$

The rather special kind of choice consistency required by WARP in the name of rational choice can be appreciated in yet another way. To make the point, some other choice-consistency conditions which are closely related to WARP must first be introduced.

Kenneth Arrow has shown that WARP is logically equivalent to the following condition, which we can call (in his honor) condition A:48

\section{A: If $S_{2} \subset S_{1}$, and $C\left(S_{1}\right) \cap S_{2}$ is not null, then $C\left(S_{2}\right)=C\left(S_{1}\right) \cap S_{2}$.}

Intuitively, condition A requires that if some alternatives are chosen out of a set $S_{1}$, and then the range of alternatives is narrowed down to a subset $S_{2}$, which still contains some previously chosen alternatives, then (i) no previously chosen alternative becomes un-

of what we might have chosen. WARP cannot easily accommodate this kind of behavior without so refining the descriptions of the alternatives for choice as to empty the choiceconsistency axiom of any real content-the alternatives are differently described to accommodate the fact that they have been chosen inconsistently. This problem of refining the descriptions, and how to control for it, is discussed by Anand, 23 Annals of Operations Research at 94-98 (cited in note 2) and Hurley, Natural Reasons at 84-101 (cited in note 7).

${ }^{47}$ For a discussion of the tendency to confuse commensurability with comparability, see Stocker, Plural and Conflicting Values at 175-78 (cited in note 31); and Cass R. Sunstein, Incommensurability in Law, 92 Mich L Rev (forthcoming 1994).

${ }^{48}$ Kenneth J. Arrow, Rational Choice Functions and Orderings, 26 Economica 121, 123 (1959). 
chosen, and (ii) no previously unchosen alternative becomes chosen. ${ }^{40}$

Amartya Sen has provided a convenient nomenclature for each of the two parts of the consequent of Arrow's choice-consistency condition A, referring to (i) as the contraction consistency property of inclusion and (ii) as the contraction consistency property of exclusion. ${ }^{50}$ Moreover, Sen has provided us with an example that attests to the apparent reasonableness of these different choice-consistency properties. ${ }^{51}$ The contraction consistency property of inclusion suggests, for example, that if Adam Smith is chosen as the best economist of all time, then he must also be chosen as among the best of the eighteenth century. The contraction consistency property of exclusion would add that if Adam Smith was (uniquely) the best of all time, then Adam Smith, and only Adam Smith, would rank as the best of the eighteenth century.

The contraction consistency property of inclusion proves to be especially important because it is one of the defining properties of virtually all the choice-consistency conditions and/or rationality requirements of social choice theory, including not only WARP, but also acyclicity and full transitivity. ${ }^{52}$ More importantly for present purposes, the contraction consistency property of inclusion also partially defines what social choice theorists refer to as path independence. ${ }^{53}$ Path (or partition) independence requires that the social choice from some set of alternatives not be a function of the agenda, or the way the alternatives are divided up for consideration. In symbols, path independence is written:

PI: $\quad C\left(S_{1} \cup S_{2}\right)=C\left(C\left(S_{1}\right) \cup C\left(S_{2}\right)\right)$ for all $S_{1}, S_{2} \in K$.

Arrow originally invoked path independence as the rationale for imposing his requirement of full transitivity on the social preference relation in social choice. ${ }^{54}$ Full transitivity, it turns out, does imply path independence, although path independence does not

40 Condition A may appear relevant only to sets of alternatives and their respective supersets, but, in fact, the conditions can be shown to imply analogous consistency requirements for overlapping choice sets, and so is equivalent to WARP. See id at 124-26.

so Sen, Social Choice Theory at 1097 (cited in note 3).

s1 See the analogous examples provided in Amartya K. Sen, Quasi-Transitivity, Rational Choice and Collective Decisions, 36 Rev Econ Stud 381, 383-84 (1969), reprinted in Amartye Sen, Choice, Welfare and Measurement 118, 122 (Blackwell, 1982).

${ }^{62}$ See Douglas H. Blair, et al, Impossibility Theorems without Collective Rationality, $13 \mathrm{~J}$ Econ Theory 361, 365-69 (1976).

${ }^{83}$ See the references cited in note 11.

st Arrow, Social Choice at 120 (cited in note 3). 
imply full transitivity. ${ }^{55}$ The two rationality conditions have in common the contraction consistency property of inclusion. ${ }^{58}$

With these conditions in hand, we can now assert how partial a view of rationality and choice consistency is really provided by the theory of social choice, all claims to the generality of the theory notwithstanding. The Adam Smith example of contraction consistency, together with the close logical connection between WARP, the rationality of preference maximization, and the concept of path independence, all combine to suggest that the model of rational social choice is very closely bound up with the logic of "good." Good, after all, is the base property for both the comparative "better," upon which rational preference and the above definition (1) of a chosen element C(S) are grounded, and the superlative "best," around which the compelling logic of the Adam Smith example turns. It is genuinely hard to think, for example, why something chosen as best in some superset (for example, as the best of all time) would not also be chosen as best in a subset (best in the eighteenth century) if it were still available for choice. This, of course, is precisely what the contraction consistency property of inclusion requires.

However, not all ethical theories are oriented toward the good. A whole family of ethical theories, and in particular many theories loosely referred to as "deontological," put the "right" prior to the good, and would be quite confused by any attempt to order social states according to their relative degrees of "rightness." The comparative "righter" and the superlative "rightest," for example, are not even well-formed under such theories. Often, theories of the right simply separate right from wrong, not by degrees, but cate-

${ }_{B S}$ Thus, on the path-independence rationale, Arrow need not have required a fully transitive social preference ordering. However, while relaxing full transitivity does provide a purely technical way to avoid Arrow's particular impossibility result for social choice, see Sen, Collective Choice at 48 (cited in note 3), the spirit of that result lives on in fully analogous impossibility theorems that use only the slightly weaker collective rationality conditions of path independence and acyclicity. See generally Blair, $13 \mathrm{~J}$ Econ Theory at 369-378 (cited in note 52). This suggests that the source of the Arrow problem is to be found in what all these impossibility results share and, more particularly, in the common rationality assumption they make.

${ }^{68}$ See Blair, $13 \mathrm{~J}$ Econ Theory at 365-369 (cited in note 52). The contraction consistency property is now often referred to as "alpha rationality" or "property alpha," or sometimes as the "Chernoff condition." See, for example, Sen, Social Choice Theory at 1097 (cited in note 3 ).

s7 For a suggestion that the transitivity of the social preference relation may be the essential defining feature of theories of the good, see John Broome, Weighing Goods 1-21 (Blackwell, 1991). Again, the structural rather than substantive nature of the claim should be emphasized. Compare the discussion in note 39 . 
gorically; it is this that can give them an absolutist flavor and, for many, renders them implausible as theories of ethical obligation. ${ }^{58}$ However, in exchange (perhaps) for having this more absolute character, theories of the right often have less scope than theories of the good. ${ }^{59}$ They typically identify and proscribe (categorically) unacceptable choices, but, within an acceptable or reasonable set of options, they do not mandate the choice of anything uniquely optimal. Arguably, this allows such theories to leave more room for the exercise of individual freedoms and the pursuit of personal projects; ${ }^{60}$ it also permits them to do less than what single-minded maximization requires, no matter what the social good at stake.

Further, deontological theories of the right, in contrast to theories of the good, emphasize more the ethical significance of the choice path-or the sequence of choice-than path independence seems to allow. It matters, for example, (indeed, it might matter categorically) whether the same end state in which someone is dead has been brought about as an act, a "killing," or as an omission, a "letting die." 61 Or it might make a difference that someone has come to be misinformed about something because of another's act of deception rather than because of a failure on that other person's part to disclose some relevant information. However, it is unclear how anything like this can matter in rational social choice theory. Under path independence, the choice sequence, or choice process, is, quite literally, inconsequential.

Of course, so brief a mention of an alternative possible ethical logic will do little to persuade a social choice theorist that she

s8 Kant provides us with a notorious example in his claim that it would be wrong for someone to lie, even if in doing so she were protecting an innocent victim from a would-be murderer. See Immanuel Kant, On a Supposed Right to Tell Lies from Benevolent Motives, in Thomas Kingsmill Abbott, trans, Kant's Critique of Practical Reason and Other Works on the Theory of Ethics 361 (Longmans, Green, 6th ed 1909). For a typical reaction to Kant's argument, see Brian Barry, And Who Is My Neighbour?, 88 Yale L J 629, 645 (1979) (reviewing Charles Fried, Right and Wrong (Harvard, 1978)).

s0 This is the tactic quite self-consciously adopted by Charles Fried, for example, to make some of the absolutist prescriptions of Kantian ethics seem more palatable. See generally Fried, Right and Wrong.

oo For an excellent development of this point in a criticism of the burdensome obligations of utilitarianism in particular, see Bernard Williams, A Critique of Utilitarianism, in J.J.C. Smart and Bernard Williams, eds, Utilitarianism: For and Against 75 (Cambridge, 1973).

6t See, for example, Judith Jarvis Thomson, Killing, Letting Die, and the Trolley Problem, 59 Monist 204 (1976). The difference between killing and letting die likely turns (in some complicated way) on the alternatives available before the chooser came upon the scene (for example, continued life or imminent death) and what choices therefore could otherwise have been made. Compare Sen's discussion of "fasting" in note 46. 
should abandon the logic of maximization and the concept of good that social choice theory would seem to presuppose. And rightly so. The point here is not to convince, but only to suggest to such theorists, as well as others who might be tempted by the theory's larger claims, that the general model of social choice may not be so general after all. ${ }^{62}$ Indeed, as the next Section will show, the logic of legal reasoning and adjudication cannot be modeled as rational social choice.

\section{Rationality IN ADJUDication}

As Michael Moore has noted, the rule of law ideal would seem to recommend a deductive logic of decision making. ${ }^{63}$ In general, deduction entails justifying one's conclusions by showing that some universal premise, which is accepted as true, subsumes or comprehends the particular facts or circumstances at issue in a more-particular situation. Specifically, normative deductions involve justifying a particular normative result by first introducing a normative predicate into the general premise, and then, again, moving by deduction from the general premise to the conclusion that the particular facts that instantiate the general premise are also to be so predicated.

This model of legal reasoning satisfies the rule of law ideal in the following ways: First, it meets the formal justice requirement, already referred to, that "like cases should be treated alike." The generalizing feature of the major premise determines the criterion for "like cases"; thus, all relevantly like cases are treated alike under the deduction. Second, the rule of law ideal that judges not make their own law is satisfied because under the deductive model the major premise is prior to, and independent of, any application it may have to the specifics of a given case. Finally, this prior positing of the major premise also satisfies the rule of law ideal of

${ }^{62}$ For related arguments, see Bruce Chapman, Individual Rights and Collective Rationality: Some Implications for Economic Analysis of Law, 10 Hofstra L Rev 455 (1982); Bruce Chapman, Individual Rights, Good Consequences, and the Theory of Social Choice, $12 \mathrm{~J}$ Theory Soc Behav 317 (1982); and Chapman, 15 Theory and Decision 1 (cited in note 18). All of these articles suggest that the rationality properties of social choice do not permit one to take individual rights partitions (those alternative social states over which an individual, as a matter of right, is to be socially decisive) seriously. Again, what alternatives exist in what partitions is, according to conditions like path (or partition) independence, quite inconsequential. For some suggestion that Amartya Sen now has comparable concerns about modeling freedom within social choice theory, see Sen, 32 European Econ Rev at 291-92 (cited in note 46).

${ }^{63}$ Michael S. Moore, The Semantics of Judging, 54 S Cal L Rev 151, 155-56 (1981). 
giving notice to those who are ultimately to be burdened by its more particular application.

But the real value of the deductive model for legal decision making is that it seems to preserve the possibility of allocating legal entitlements so that some real good can be achieved through law. This is because the conscious achievement of good through the allocation of legal entitlements would seem to be necessarily deductive in nature. The major premise identifies the general principle or good toward which the allocation is to be oriented (for example, the maximization of wealth), and, within this premise, the normative predicate takes the form of a legal benefit or burden that is to be so distributed. To continue the example, the major premise in a wealth-maximizing scheme involving the costs of accidents might be: "To maximize wealth, the least cost avoider of the accident should bear liability for its costs." The minor premise would then go on to identify which person was the least cost avoider, and a conclusion as to liability based on wealth-maximizing concerns would immediately follow. ${ }^{64}$

Thus, the model of deduction argues for a very special kind of connection between the two things most often identified as the stuff of law, namely, rules and cases. In deduction, the rules are prior to the cases, that is, the rule is independently determined and brought to bear on the facts of the case if the case is one of those subsumed under the rule. This is, of course, the reason why the deductive model is so enticing to those theorists motivated by the sorts of normative concerns identified above.

However, the priority of rules to cases, even though it might appear to make the model of deduction normatively attractive, also renders it implausible as a proper description of judicial law making. If anything, in legal reasoning rules have a role that is secondary to cases. This is reflected in the frequent criticism among firstyear law students (before they come to "think like a lawyer") that they never seem to learn the law (by which they mean its rules), but are only confronted (under the so-called Socratic method) with an endless series of new cases and hypotheticals that, within some area of the law, constantly upsets any attempts they might make to bring order to the chaos by stipulating a rule for it all. This

* The term "immediately" should not be thought to suggest that the calculus involved in such a scheme is easy; on the contrary, it will typically be quite difficult, for example, to determine who is the least cost avoider of an accident. Rather, "immediately" only refers to the gapless, truth-preserving entailment which is so characteristic of, and compelling in, deduction. 
craving for a once-and-for-all rule, of course, is just the craving for the apparent certainty of deduction, something to which Wittgenstein alluded in another context:

This craving for generality is the resultant of a number of tendencies connected with particular philosophical confusions. There is-(a) [t] he tendency to look for something in common to all the entities which we commonly subsume under a general term. . . . [and] (b) [the] tendency rooted in our usual forms of expression, to think that the man who has learnt to understand a general term, say, the term "leaf," has thereby come to possess a kind of general picture of a leaf, as opposed to pictures of particular leaves. ${ }^{65}$

In law schools, when this craving for generality is not satisfied, many students become cynical or skeptical that much at all is systematic in legal reasoning.

Nevertheless, it seems plausible to argue that there is something systematic and reasonable going on in common law adjudication, even if it is not deductive. ${ }^{66}$ What justifies a particular decision on a given set of facts in adjudication is not some prior and independent normative rule that subsumes the facts (a relation between the general and the particular), but rather just a relation that the given facts bear to the facts of some earlier decision (a relation between two particulars). ${ }^{67}$ Specifically, the methods of legal reasoning require that relevantly similar cases must be decided 1969).

${ }^{6 s}$ Ludwig Wittgenstein, The Blue and Brown Books 17-18 (Barnes \& Noble, 2d ed

The contrast between what is reasonable in law and what is rational in deduction is highlighted in Chaim Perelman, The Rational and the Reasonable, in Perelman, The New Rhetoric and the Humanities: Essays on Rhetoric and Its Applications 117 (Reidel, 1979):

The existence of two adjectives, 'rational' and 'reasonable,' both derived from the same noun, and designating a conformity with reason, would pose no problem if the two terms were interchangeable. But, most often, it is not so. We understand the expression rational deduction as conformity to the rules of logic, but we cannot speak of a reasonable deduction. On the contrary, we can speak of a reasonable compromise and not of a rational compromise.

I like to think that in this Article I have captured something of what Perelman might have meant by these remarks, and that he will not object if I borrow his title to use as my own so that I can signal this affinity.

${ }^{67}$ Compare Hannu Tapani Klami, Legal Argument and Decision Theory, 37 Am J Juris 171, 177 (1992):

... [T] $[$ me main point is that the application of such norms directly referring to principles and evaluations soon will turn to quite ordinary sources-of-law operations. Judicial practice will create precedents, and then a decision maker will compare cases to cases (or opinions of the juristic authorities) and he will resort to the principles only after having failed to find sufficient guidance for his decision at this level of decision-making. 
the same way, unless one can point to some relevant difference between them. In other words, the formal justice value which would have us treat "like cases alike" is more than just an attractive secondary normative implication of achieving some substantive good in the cases through deduction. Rather, it is the primary organizing principle for the cases themselves.

As already suggested, this will strike many as hopeless selfdelusion. For them, the principle of formal justice is essentially an empty idea and, therefore, useless as a practical guide to deciding cases. ${ }^{68}$ In construing two situations as "similar" or even "identical," and demanding as a matter of formal justice that they be accorded similar or identical treatment, one is obviously ignoring some actual differences as irrelevant, and looking unsuccessfully for other relevant differences that might have distinguished the cases. (The situations are two, after all, even if they are otherwise identical.) The selection of what is relevant and irrelevant to these judgments of similarity and difference is where all the real normative work is done. Moreover, it will be further objected that this is where the prior ordering of deductive rules must inevitably come into play. It is these prior rules which point to the relevant similarities and differences between the cases.

But this idea that the prior rules of deduction must be reintroduced to deal with the required judgments of similarity and difference between cases is almost certainly incorrect. While a judge might state her conclusion in the form of some general rule that, ex post, points to a rule that either does (in the case of like cases being treated alike) or does not (in the case of relevantly different cases) subsume both cases in question, the rule is just that, a conclusion, and it is not the reason for the result. ${ }^{69}$ If the judge refers to prior rules at all in coming to her decision, it is usually to point to rules in earlier cases that are either "too broad" (and, despite initial appearances, therefore, should not embrace the instant case) or "too narrow" (and should). But in neither situation is it the rule as articulated in the earlier case that determines the outcome in the instant case. That would be impossible, since it is the rule itself, if it is referred to at all, that undergoes transformation.

${ }^{68}$ See, for example, Westen, 95 Harv L Rev 537 (cited in note 39).

69 Compare Steven J. Burton, An Introduction to Law and Legal Reasoning 59 (Little, Brown, 1985): "The common law rules help lawyers and judges express themselves economically and organize the precedents, though analogical reasoning from the precedents remains the underlying mode of thought." The seminal modern source for the view that legal reasoning proceeds by analogy or example, and not by rule, is Edward H. Levi, An Introduction to Legal Reasoning (Chicago, 1948), particularly at 1-27. 
Rather than appeal to a rule or, equivalently, to a whole set of necessary and sufficient conditions that, at some meta-level, define a further rule for the first rule's application, ${ }^{70}$ a judge typically determines similarity and difference between cases by looking only to very specific, even singular, features of each case as compared to earlier cases. A rule articulated in some earlier case will either be deemed too broad, because it has failed to mention some particular feature of the earlier case (not present in the instant one) that was necessary for its result, or too narrow, because it has mentioned some other feature (also not present in the instant case) that was not necessary for the result, or, perhaps, both. But all of this the judge can do without articulating anything like a full set of necessary and sufficient defining conditions for the proper application of a rule, and certainly without providing any kind of endorsement of a previous judicial attempt to do so.

To see this adjudicative process more clearly, it is instructive to consider the following abstract example, presented in summary form in Figure $1 .^{71}$ Imagine that we are in a status quo ante legal state $\mathrm{L}_{1}$, characterized (in column (1) of the figure) by the norma-

${ }^{70}$ We obviously cannot go on constructing rules for the proper application of other rules in hopelessly infinite regress. There must be a point when the rules for applying the rules simply run out. At that point, one simply exercises one's judgment and, non-deductively, follows the rule which then applies. Indeed, given the problem of infinite regress, that is all it could possibly mean to follow a rule. To think otherwise, or to think that there is some significant "indeterminacy" here, as some legal skeptics seem prone to do, is to fall prey to the sort of confusion that Ludwig Wittgenstein meant to clear up in some wellknown passages on "rule following" in Ludwig Wittgenstein, G.E.M. Anscombe, trans, Philosophical Investigations $\S \S 201-02,217$ (Blackwell, 2d ed 1958). For an excellent discussion of this point, see Brian Langille, Revolution Without Foundation: The Grammar of Skepticism and Law, 33 McGill L J 451, 486-99 (1983).

Even Kant, a thinker obviously bent on determining the rules of pure reason, had to admit that into all acts of judgment must inevitably enter personal decisions that cannot be accounted for by rules. For both Wittgenstein and Kant, this was the point at which some particular must be judged to fall under a general rule or universal category. Kant referred to the intellectual capacity to make such judgments as "mother wit," and declared it quite inscrutable. See Immanuel Kant, J.M.D. Meiklejohn, trans, Critique of Pure Reason 115 (Dent, 1934). For a discussion, see Michael Polanyi, Experience and the Perception of Pattern, in Kenneth M. Sayre and Frederick J. Crosson, eds, The Modeling of Mind 207 (Notre Dame, 1963).

${ }^{71}$ I have used the following abstract example to make a related point in Bruce Chapman, Tort Law Reasoning and the Achievement of Good, in Ken Cooper-Stevenson and Elaine Gibson, eds, Tort Theory 73, 87-101 (Captus, 1993). Although not explicitly modeled on it, the structure of my example appears consistent with the computer model for caseoriented legal reasoning (called "Hypo") that has been developed by Kevin Ashley. See Kevin D. Ashley, Modeling Legal Argument: Reasoning with Cases and Hypotheticals (MTT, 1990), especially at 25-34, and 157-67. Ashley's model is also discussed in Edwina L. Rissland, Artificial Intelligence and Law: Stepping Stones to a Model of Legal Reasoning, 99 Yale L J 1957, 1971-75 (1990); and Hurley, Natural Reasons at 416 n 25 (cited in note 7). 
tively and legally relevant features $r, s$, and $t .^{72}$ Let us suppose that while in $\mathrm{L}_{1}$, we thought that $r$ was the rule, or the most salient defining feature of the legal state. ${ }^{73}$ Thus, we might just as easily say that while in $L_{1}$ we are in legal state $r$. One might think of $r$ as a rule summarizing the set of factors necessary and sufficient for a plaintiff to win a certain sort of case or, alternatively, as the rule organizing a set of cases under some legal doctrine. (Other rules, therefore, will summarize a set of cases in which the defendant might win, or a set of cases under a different legal doctrine.) In this respect, $r$ appears to be the sort of rule that promises to inform a deductive approach to such cases. But, as we shall see, this promise will not be kept.

Figure 1

\section{Rational Adjudication of Like Cases}

(1)

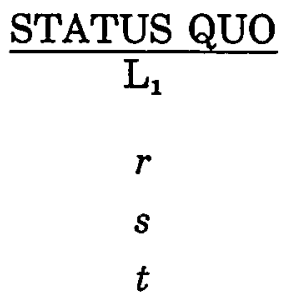

(2)

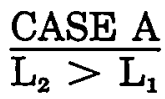

$s$

$t$

$u$
(3)

$\frac{\text { CASE B }}{\mathrm{L}_{3}>\mathrm{L}_{2}}$
$t$
$u$
$r$

(4)

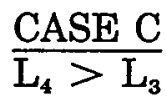

$u$

$r$

$s$
(5) $\frac{\text { CASE D }}{\mathrm{L}_{1}>\mathrm{L}_{4}}$ $r$ $s$ $t$

Along comes a legal case A, in which some litigant proposes a change to legal state $\mathrm{L}_{2}$ with characterizing features $s, t$, and $u$ (as

The abstract example discussed in the text is also similar to that used by Lord Diplock in his summary of the nature of judicial law making in Dorset Yacht Co. $v$ Home Office, [1970] App Cas 1004, 1058-60 (HL 1970). This case is considered at length in Section III.

72 I use the term "legal state" rather than the more usual term "social state" to indicate that the alternatives for choice here vary with changes in legally relevant features in the descriptions of the social states. A judge chooses a legal state by considering these various legal features, perhaps rejecting some as legally irrelevant, and raising one to the status of a defining rule for the state.

73 Thus, in the Figure 1 matrix, the characterizing legal features of a legal state appear in the columns, and the defining legal feature or rule for the legal state appears in the top row of each column. At this point in the analysis, therefore, there is no special significance to the order (from top to bottom) of the legal features beyond the first row. However, in Section III, this order does become important. Legal features, which might begin as only "traces" of legal concern or notice in the bottom row of a given case column, will rise to higher status in another case, say, as evidence of the more important legal feature that defines the rule. Finally, in yet another case, the feature becomes the basis for the rule itself. 
shown in column (2) in Figure 1 ). $\mathrm{L}_{2}$ appears very similar to $\mathrm{L}_{1}$, with case A a "like case" to whatever case it was that originally defined legal state $\mathrm{L}_{1}$, in that both $\mathrm{L}_{1}$ and $\mathrm{L}_{2}$ have features $s$ and $t$. The social states differ, of course, in that $\mathrm{L}_{2}$ does not have the feature $r$ that seemed so salient in $\mathrm{L}_{1}$. But suppose that the similar features $s$ and $t$ between the cases, or legal states, trump this difference in the judge's mind, and she chooses to change the legal state to $L_{2}{ }^{74}$ This choice of $L_{2}$ over $L_{1}$ is indicated as $L_{2}>L_{1}$ at the top of column (2) in Figure 1.

Now the judge in case A might be tempted to articulate a new and broader rule, or salient defining feature, for this new larger set of like cases that includes case A. She might, for example, want to say that the feature that makes sense of all the prior cases, as well as the legal state $\mathrm{L}_{2}$ we are now in, is the feature $s$ that, while it did not define $\mathrm{L}_{1}$ originally, now looks salient given the like case $\mathrm{A}$ and the fact that this feature is also characteristic of $L_{2}$. So she defines $s$ as the defining rule for $\mathrm{L}_{2}$, a rule that links all the like cases in $\mathrm{L}_{1}$ and $\mathrm{L}_{2}$.

However, consider now case B in column (3), which proposes legal state $\mathrm{L}_{3}$ characterized by features $t, u$, and $r$. Again, case $\mathrm{B}$ seems to be a like case to case $A$, with $L_{3}$ very similar as a legal state to $\mathrm{L}_{2}$ in that it shares the features $t$ and $u$. Moreover, note that $L_{3}$ is just as similar to $L_{1}$, since it also has two features in common with that legal state, features $r$ and $t$. So the judge in case B feels compelled to support the proposal to move to $L_{3}$ and, again, attempts to articulate the rule or defining feature that brings order to $\mathrm{L}_{3}$ and all these like cases. The feature that all three social states have in common, of course, is feature $t$, and the judge confidently announces this feature as defining the rule in legal state $L_{3}$, a rule now broad enough, surely, to cover all the like cases.

Alas, along comes case $\mathrm{C}$, proposing legal state $\mathrm{L}_{4}$ characterized by features $u, r$, and $s$ in column (4) of the figure. For all the analogous reasons, case $\mathrm{C}$ appears to be a like case to cases $\mathrm{A}$ and $B$, and whatever earlier case it was that helped to characterize $L_{1}$, and so the judge feels obligated to accept the proposal to move to

${ }^{74}$ It may seem arbitrary at this point first to propose a rule and then, at the first opportunity, to change it. However, this example will demonstrate that the change is not arbitrary, but only appears so under a deductive approach to the problem. Thus, the reader is encouraged to read on. Moreover, since the point of the exercise is to investigate the properties of consistent choice in the adjudication of legal rules, and to contrast them with the properties of rational social choice, an apparently new choice of legal rules is required to give that exercise content. 
$\mathrm{L}_{4} . \mathrm{L}_{4}$ seems as compelling a proposal for legal change as any earlier one even though $\mathrm{L}_{4}$ does not have the defining feature $t$ that seemed so salient as the rule linking all the like cases up to $L_{3}$. Could this be because the real rule should properly be defined by the feature $u$ that links all the compelling changes to legal states $L_{2}, L_{3}$, and $L_{4}$, even though that is not a feature of $L_{1}$ ?

Perhaps $L_{1}$ is now to be reformed away as an inferior social state with its apparently "like case" overruled. Perhaps the rule that defines feature $u$ as salient is a "better" (although in some sense a narrower) legal rule than any rule that allowed for the inclusion of the "like case" in $\mathrm{L}_{1}$. Indeed, we may be tempted to think that there is an ordering of rules (and legal states) here, in particular, that "rule $u$ " in $\mathrm{L}_{4}$ is preferred to "rule $t$ " in $\mathrm{L}_{3}$, that "rule $t$ " in $\mathrm{L}_{3}$ is preferred to "rule $s$ " in $\mathrm{L}_{2}$, and that "rule $s$ " in $\mathrm{L}_{2}$ is preferred to "rule $r$ " in $\mathrm{L}_{1}{ }^{75}$ In other words, we may be tempted to think that this whole progression of legal cases has been for the better, bringing us steadily forward into some most preferred social state as defined by some most preferred legal rule.

However, if that is so, what are we to say when case $D$ comes along? Case $\mathrm{D}$ proposes $\mathrm{L}_{1}$ with its characterizing features $r$, and $t$ in column (5). Surely, case D is as much a "like case" as any we have seen so far, with the proposed $\mathrm{L}_{1}$ sharing two features in common with each and every legal state $\mathrm{L}_{2}, \mathrm{~L}_{3}$, and $\mathrm{L}_{4}$. Does this not make the move back to $L_{1}$ just as compelling as any legal change so far proposed? It seems so, but now it is hard to think that this sequence of legal changes has been for the better since we are back to where we started; column (5) reproduces column (1). Indeed, case $\mathrm{D}$ (or one very much like it) might have been the case that helped to define legal state $L_{1}$ in the first place. Either the whole sequence is irrational because, as the rational choice theorist might say, it is not acyclical, or the notion of what is rational in the incremental development of "like cases" in the law is fundamentally different from that which progressively chooses more preferred legal states or legal rules.

The legal skeptic might support the view that the legal reasoning exemplified here is not rational. To be sure, reasons are provided for the grouping and distinguishing of cases, or the choosing of rules, with these reasons focusing on the normatively and legally relevant characterizing features of each social state. But the reasons can vary from case to case within a group of so-called like

73 Compare Easterbrook's discussion, in the text accompanying note 29, of the need for an ordering of constitutional principles. 
cases. For example, case $\mathrm{D}$ and case $\mathrm{C}$ (proposing $\mathrm{L}_{1}$ and $\mathrm{L}_{4}$ respectively) might be likened to one another because they share the proposed features $r$ and $s$, but case D will be likened to case A (proposing $\mathrm{L}_{2}$ ) because they share proposed features $s$ and $t$. Thus, the same reasons are not necessarily going to be provided for likening any one case to another within the same set of like cases, and this could be true for all possible pairs of cases so far identified as falling within the set. Indeed, this is true for the four cases, A through $\mathrm{D}$, discussed here.

Moreover, since case A is linked with case B by features $t$ and $u$, and case $\mathrm{C}$ is linked with case $\mathrm{D}$ by features $r$ and $s$, then not only are the same reasons not being provided for similarity judgments from case to case, but also, for some pairs of cases, there may not even be any overlap in the reasons provided for the different pair-wise comparisons of the like cases involved. Thus, there may be more than a mere failure to use identical reasoning as one moves between the different pairs of cases within a set of so-called like cases. More strongly, it could also be that the sets of reasons offered for moving between different pairs of cases within a set of so-called like cases are totally disjoint or unconnected. ${ }^{76}$ Moreover, the reasons used in moving from case $A$ to case $B$ are not only disjoint with the reasons used in moving from case $C$ to case $D$, but the effect of these two moves in combination appears to be the simultaneous rejection and reassertion of legal state $L_{1}$, surely the stuff of contradiction and inconsistency.

It is small wonder, therefore, that the legal skeptic might think that nothing really systematic goes on within some legal domain of allegedly like cases. The skeptic will suggest, just as a rational choice theorist might, that it is not enough for the rationality of a decision-making process that some reasons are offered for the various decisions being made. Rather, the reasons offered must bear some rational relation to one another. They must, in other words, be consistent, manifesting some common principle. Anything less is mere confusion.

${ }^{76}$ One might object that judges never consider only a pair of cases, the instant case and the immediately preceding precedent, as the argument in the text suggests. Rather, judges will look back to a sequence of several precedents. However, this Article's argument does not turn on the fact that, for purposes of easy exposition, it distinguishes the reasons that link different pairs of cases within a larger set of like cases. It might also have used an example in which each of the subsets of the larger set were themselves larger than pairs, but for which the reasoning within any of these subsets still revealed no one reason in common across all the subsets, nor even, for some combinations of the subsets, any one reason that was connected. 
All this is as it might be-but not as it need be. Rather, the confusion might be the confusion of someone looking for rational deduction where there is none. To be sure, deduction, because it provides a true universal for the subsumption of any particular case into the general category of like cases, would provide one and only one reason for all particular judgments of relevantly similar cases. The singular feature $r$, initially identified as the defining feature for $\mathrm{L}_{1}$, for example, would in that situation persevere to order all the cases. But in the development of like cases under formal justice, as just now exemplified by the analysis surrounding Figure 1 , this need not be so; there may be no single reason that rationalizes all the judgments of like cases in a given legal context. There may not even be any obvious connection or overlap between the reasons provided for certain judgments of similarity between different pairs of such cases. Nevertheless, there does seem to be something manifestly reasonable in the development of such a set of like cases. ${ }^{77}$

It is tempting, of course, to think that if there is not just confusion here, there is at least a failure to articulate the rule, or universal predicate, that really informs the judgments around this set of like cases. Thus, the rationality exhibited here is deductive, even if it is not perceived as such.

But why assume that at all? Why assume that the ordering of like cases is cognitive (or a "reasoning why" process) rather than perceptive (a "seeing that" process)? ${ }^{78}$ When we recognize a

77 Compare Perelman, The Rational and the Reasonable at 123 (cited in note 66):

The idea of the reasonable intervenes in law in the absence of a theory which would furnish more precise criteria for the basis of a decision. . . . All theories elaborated in this regard are shown to be unsatisfactory and very often, with complex situations, judges refer to what is reasonable, to justify their decisions without being able to formulate a precise rule which would be applicable in all cases of this kind.

${ }^{78}$ For an extended discussion of the importance of distinguishing "reasoning why" from "seeing that," see Howard Margolis, Patterns, Thinking, and Cognition 68-86 (Chicago, 1987). See also Martha C. Nussbaum, The Discernment of Perception: An Aristotelian Conception of Private and Public Rationality, in Martha C. Nussbaum, Love's Knowledge 54 (Oxford, 1990). In Margolis's view, the process of reaching a judgment is much more "seeing that" than "reasoning why," while the latter is more important for justifying a judgment after the fact. This corresponds to this Article's claim that legal rules rationalize the conclusions of legal judgments already reached on other grounds, but are not themselves the basis for the legal judgments made.

Margolis's general view is that cognitive processes of all kinds are first and foremost processes of pattern recognition, with the algorithmic, rule-generating rationalizations always secondary. Social controls on the subjectivity of these processes are imposed through language patterns. Some patterns are more easily articulated through the language than others, and, therefore, are more easily held onto as starting points for the next moment of pattern recognition. Margolis argues: 
friend's face as the same face we have always known, not only do we not have any conscious sense of how that judgment was reached, it would not even occur to us that we should be able to articulate how we came to that judgment. The judgment, as we know, simply does not come about that way. Even in situations where there is a conscious sense of "figuring out" prior to the judgment, as when we stare at and finally decipher a blurred image, we can rarely say very much at all about what constitutes that "figuring." But we do not think that our inability to do so provides any reason for thinking that we figured it wrong, or that our judgment might be better supported if we could only unpack the logic that generated it. We simply come to see the image after some study and, further, "know it when we see it."

This last phrase brings us directly back to legal judgment, since Justice Stewart used it as an explanation of how he was able to tell when a particular book or film was pornographic. ${ }^{79}$ If there were no more to any legal conclusion, we would likely say that this is not an explanation of anything, and that the reasons have run out far too soon. ${ }^{80}$ However, the model of formal justice outlined

A consequence is that our thinking will be biased toward "bundle-able" or "patternable" sequences, so that what we find plausible and comprehensible is intimately tied to what can be assimilated to patterns already in our repertoire and built out of bundles (smaller patterns) already in our repertoire.

Margolis, Patterns, Thinking, and Cognition at 77. We can see in this the beginnings of a theory of path- (or partition-) dependent reasoning.

In another Article, I have argued that certain choice sequences or processes are socially privileged, or appear more "natural" for us, because the choice partitions they use are more easily captured in the language and concepts we share. See Bruce Chapman, Rational Environmental Choice: Lessons for Economics from Law and Ethics, 6 Can J L Juris 63, 82-87 (1993). For comparable arguments that language might discipline descriptions of the alternatives for choice to the same useful effect, see Anand, 23 Annals of Operations Research at 96-97 (cited in note 2); Hurley, Natural Reasons at 84-101 (cited in note 7). We can only "see" these more natural partitions of the alternatives, however, in the context of a particular choice situation. They would not be apparent in abstract, purely logical or mathematical formulations of a choice problem. This may explain why there is little sensitivity in rational choice theory to the role contextual factors might play in disciplining coherent choice. Rational choice theory is distinguished for its use of pure mathematics and, as Bertrand Russell has observed, mathematics could be defined as the subject in which the interlocutors never know exactly what they are talking about.

Finally, for an application of this type of "partition-sensitive" analysis in a legislative context, see Bruce Chapman and Michael J. Trebilcock, Making Hard Social Choices: Lessons from the Auto Accident Compensation Debate, 44 Rutgers L Rev 797, $849-67$ (1992).

${ }_{78}$ Jacobellis $v$ Ohio, 378 US 184, 197 (1964) (Stewart concurring).

so See Anthony Kronman, Practical Wisdom and Professional Character, 4 Social Phil \& Pub Pol 203, 209-19 (1986), where, in discussing Justice Stewart's comment, he also suggests that something more than mere intuition or insight is needed if a judgment like Stewart's is to be grounded at all. While suggestive of the true nature of legal judgment, Kronman argues that Stewart's approach allows too much of a role for mere "looking" or 
above is more than that. It shows that reasons have a role to play in adjudication. Cases are likened to, or distinguished from, other cases, all for good reasons. Moreover, all the reasons within some doctrinal area of like cases bear a rational relationship to one another. The point is not merely that the final legal conclusion "just looks right," but rather that all the reasons behind that conclusion look right because they are rationally related to the reasons for other like cases, that is, they form an integrated or coherent whole

\footnotetext{
"seeing that," and not enough of a role for thought. Kronman finds the additional something that is required in a synthesis of "thinking" and "looking," a synthesis achieved, he argues (borrowing from Kant), when the powers of imagination are exercised. Id at 210-13. Imagination, more than merely abstract thought, conjures up a concrete and vivid image that we see, but, because we see it "with the mind's eye," the image is also the product of our own thought. Id at 212 . As a product of thought, the image we see in our imagination is "more fully subject to our powers of revision and denial" than are the objects we see in the real world. Kronman compares this imaginative process of revision and denial to the deliberative processes of legal judgment in which the concrete particulars of a given case constantly "influence the shape and content of the rules that we normally think of as forming the conceptual framework of the adjudicative process itself." Id at 215. Kronman continues: A judge simultaneously looks to see what existing legal rules imply for the case at hand and what that same case implies for the rules themselves. His deliberations cannot, therefore, be adequately conceived merely as a process of subsumption in which particular instances are brought under established and unchanging categories. A judge moves back and forth between cases and categories, adjusting his view of each in light of the other. This is a fluid and dynamical process which results not only in judgments about particular cases but also in the ongoing revision of the system of rules in accordance with which subsequent disputes must be decided.
}

Id.

In the final analysis, Kronman argues that a legal decision displays practical wisdom not when the intellectual machinery of rules and categories is brought to bear on the particular facts of the case with impeccable accuracy but isolated from the actual outcome of the case (as in the worst cases of "mechanical jurisprudence"), nor when a claim is made about the actual factual outcome of a case independent of any reasons provided to support it (as in Justice Stewart's bare insight). Rather, there is practical wisdom when there is "a certain harmonious relationship between the intellectual apparatus of a case and its factual peculiarities, a relationship in which the elements [of fact and argument] are not merely stuck together in a mechanical fashion but are synthetically united in a way that strengthens each ...." Id at 219 .

This Article emphasizes this same "self-strengthening integrity" of a set of mutually supporting reasons as seen and developed in the context of a set of like cases. As argued in the text, the judgment of a like case is neither to be determined according to the mechanical application of some single overarching and decisive rule, nor proclaimed as an insight unsupported by any argument at all. Rather, reasons are offered, perhaps even different reasons from case to case, but these reasons are compelling over the set of like cases because they create a self-strengthening integrity. Compare Raz's characterization of "coherence," 72 BU L Rev at 277 (cited in note 7):

[P]hilosophers use "coherent" to mean something like "mutually supporting." Two beliefs cohere if each makes belief in the other more reasonable than its rejection. . . . Let us say that if beliefs fit together they are mutually reinforcing, using "fit together" in place of whatever relation(s) between propositions makes them cohere, i.e., makes them mutually reinforcing. 
in which all of these other reasons participate as parts. Finally, this is something we can say of them even though we cannot point to any single feature that makes sense of, or is common to, all of them together. ${ }^{81}$ Thus, Justice Stewart's comment is better interpreted as indicating not that "seeing that" is all there is, but that there is a point where "reasoning why" runs out, and "seeing that" must inevitably begin.

If the process of judgment is, sometimes at least, not something to be articulated as a "reasoning why," then clearly it will be very difficult to teach to others. There will be, at least at some key points, no rules to learn. Yet law is something we do teach, and something we do learn. Does this not suggest that legal decision making must be algorithmic after all? Again, the answer must be no. As already remarked, when we learn the law initially as students, we learn it through a reading of the cases, constantly posing questions under new hypotheticals, where only very particular fea-

B1 The purely internal logic of related reasons might be usefully illuminated by an image of Gadamer's. See Hans-Georg Gadamer, Truth and Method 293-94 (Seabury, 1975). A realistic painting "just looks right" if all its various lines of perspective converge on some one "vanishing point." Now we might be tempted to say that the vanishing point provides "the rule" for drawing a line in the painting, but it is clear that it cannot provide any such rule before some part of the painting is already filled in. A blank canvas could have any point on it as a vanishing point, albeit for different paintings. Thus, it is the filling in of some part of the painting that disciplines the filling in of the rest of that painting. In this sense, the logic of painting realistically (rationally?) is internal to the decisions already revealed by a particular painting. I am grateful to Ernie Weinrib for bringing Gadamer's metaphor of the vanishing point to my attention. See Ernest J. Weinrib, Aristotle's Forms of Justice, 2 Ratio Juris 211, 221 (1989).

But do we have to say that, if all the lines of perspective for a given painting converge on one vanishing point, then all those lines share a common feature, just as deductive reasoning seems to require? It seems so, but now appearance has taken over reality. It may be a good practical guide for realistic painting to have all the lines of perspective meet at some vanishing point, but it would be a mistake to think that this is true of what the lines represent in reality. For example, although we might paint them that way, the rails of a railway track do not actually meet on the horizon. (Rene Magritte has had some fun with this particular confusion in his painting.) Better is the view recognizing, first, that the "vanishing point rule" is a useful guide to painting realistically, much as rules of law are to deciding judicially, but that second, as a universal truth, it is manifestly false.

Lord Diplock has made the same point against Lord Atkin's famous "neighbour principle" as a "general conception of relations giving rise to a duty of care" in tort law as set out in Donoghue $v$ Stevenson, [1932] App Cas 562, 580 (HL 1932). Lord Diplock remarks in Dorset Yacht Co. $v$ Home Office, [1970] App Cas 1004, 1060 (HL 1970):

Used as a guide to characteristics which will be found to exist in conduct and relationships which give rise to a legal duty of care this aphorism marks a milestone in the modern development of the law of negligence. But misused as a universal it is manifestly false.

Both Lord Atkin's principle, and Lord Diplock's own attempt to articulate a universal organizing principle for the duty of care in tort law, are examined in greater detail in Section III. 
tures of the case have been changed to test our developing intuitions. This is as close as the law school environment can come to an actual series of "seeing that" experiences. Later, we apprentice as law clerks to "learn by doing" from those well-practiced in the exercise of legal judgment. Again, we do this not to learn more rules, nor even the more practical rules of legal procedure, but rather, through direct observation, to acquire knowledge of (or even, we might say, "get a feel for") how a skilled practitioner of a craft sets about doing her business, including the practical wisdom of how and when to apply what rules there are. None of this makes sense unless we recognize that the mastery of law is more than the mastery of a set of rules ordering the cases. ${ }^{82}$ On the latter view, it would be better to read legal textbooks, which provide tidy rationalizations of the cases, than to read the cases themselves, and better to substitute quiet and isolated reflection for the daily confusions of on-site "muddling through." That we have chosen to learn the law the other way is some testimony to the truth of Holmes's well-known claim that the life of the law is not logic, but experience. ${ }^{83}$

Moreover, we can now see why the logic of rational social choice is not the lifeblood of judicial law making. For if the reasoning provided in a given case for moving between any two legally defined social states is a function of what those particular social states have in common, and if there need be no common feature for a whole set of like social states (and the "like cases" linking them), then the choice of the defining rule for any given social state attempting to bring order to some particular subset of the like cases will inevitably depend on how the different alternatives have been partitioned for choice. 1991):

${ }^{82}$ See Michael Oakeshott, Rationalism in Politics and Other Essays 15 (Liberty, 2d ed

Technical knowledge can be learned from a book; it can be learned in a correspondence course. Moreover, much of it can be learned by heart, repeated by rote, and applied mechanically: the logic of the syllogism is a technique of this kind. Technical knowledge, in short, can be both taught and learned in the simplest meanings of these words. On the other hand, practical knowledge can neither be taught nor learned, but only imparted and acquired. It exists only in practice, and the only way to acquire it is by apprenticeship to a master-not because the master can teach it (he cannot), but because it can be acquired only by continuous contact with one who is perpetually practicing it. In the arts and in natural science what normally happens is that the pupil, in being taught and in learning the technique from his master, discovers himself to have acquired also another sort of knowledge than merely technical knowledge, without it ever having been precisely imparted and often without being able to say precisely what it is.

ss Oliver Wendell Holmes', Jr., The Common Law 1 (Little, Brown, 1923). 
To see the point, consider again the revealed preference axiom WARP. Recall that WARP required that if some alternative $x$ were chosen over another alternative $y$ in a choice set $S_{1}$, then for no set $\mathrm{S}_{2}$ could alternative $y$ be chosen over alternative $x$. This choice-consistency condition, it was suggested, ${ }^{84}$ would make sense if the motivations for choice were only to be found in the properties possessed by the alternatives for choice. Then one would reasonably expect the choices over these alternatives with these intrinsically important properties to be invariant with changes in the choice set, that is, invariant with additions and subtractions of other alternatives. On the other hand, when the choice set might be thought to define different issues simply because differently related alternatives were available for choice, then it is less apparent that WARP is a reasonable requirement. This dependency of issues on the choice set, and the relations that might exist between alternatives, is what characterizes the choice among legal rules defining different social states.

Suppose the issue in the case is to choose one of the legal features of the proposed social state as a legal rule to bring order not only to the cases already decided but also to the instant case, which is reasonably believed to be a "like case." Suppose, for example, we are in case $C$ in Figure 1 , which proposes legal state $L_{4}$, having already decided cases $\mathrm{A}$ and $\mathrm{B}$. Then, of the characterizing legal features $u, r$, and $s$ in $\mathrm{L}_{4}$, which are available as a possible definitive feature or rule for these three cases, the judge in case $\mathrm{C}$ would be tempted to choose feature $u$ as "best." That, as we have already seen, is the feature common to these three cases. However, suppose, by contrast, that we were in case $A$, which proposes $L_{2}$, this time having already decided cases $C$ and $D$. Then, of the characterizing features $s, t$, and $u$ in $\mathrm{L}_{2}$, all of which are available as possible choices for the organizing rule in the three cases, the judge would choose $s$ as "best." This is the feature common to these three cases. Thus, while in case $\mathrm{C}$ the organizing feature or rule chosen as "best" for the cases A, B and C would be feature $u$ (not feature $r$ or $s$ ), in case A the organizing feature or rule chosen as "best" for the cases C, D, and A, would be feature $s$ (not features $t$ or $u$ ). This choice of feature $u$ over feature $s$ as the rule in one case in which the choice set was $(u, r, s)$, together with the choice of feature $s$ over feature $u$ as the rule in another case in which the choice set was $(s, t, u)$ would violate the choice-consistency condi-

\footnotetext{
84 See text accompanying note 40 .
} 
tion WARP. Certainly, these choices do seem to strain any straightforward characterization of them as choices for the "better" or for the "best," since legal feature $u$ is revealed by these choices to be both better and worse than legal feature $s$.

This analysis also serves to show how legal decision making violates the closely related path-independence property of rational social choice. Think of the legal problem now as choosing which of the legal features $r, s, t$, or $u$ should be construed as bringing order to this whole set of like cases. Thus, the overall choice is from the set $(r, s, t, u)$. This overall choice can be partitioned further into a choice from the subsets $(s, t, u),(t, u, r)$, and $(u, r, s)$. If path independence applies, this partitioning of the alternatives should yield the same choice as the choice partition that chooses from the subsets $(u, r, s),(r, s, t)$, and $(s, t, u)$. But the first choice partition is effectively a choice over the rules that have already been chosen to rationalize the cases $\mathrm{A}, \mathrm{B}$, and $\mathrm{C}$ respectively, and is, therefore, reducible to a choice from the set $(s, t, u)$. For example, the choice from the first subset of the first partition, the set $(s, t, u)$, is effectively a choice of that feature in column (2) of Figure 1 that should be chosen from $L_{2}$ so as to make sense of $L_{2}$ as a like legal state to $\mathrm{L}_{1}$. This, as we have seen, is feature $s$. A fully analogous argument applies for the second and third sets of the first partition; hence, the overall choice is reduced to the choice over the set $(s, t, u)$. On the other hand, the second choice partition is a choice over the rules used to rationalize the cases $\mathrm{C}, \mathrm{D}$, and $\mathrm{A}$ respectively, and is, therefore, on fully analogous arguments, reducible to a choice from the set $(u, r, s)$.

Now, before we can continue, we need to make a distinction between rationalizing, or providing a rule for, the choice of one like case, and rationalizing, or providing a rule for, a series of such cases. As just described, we would choose $s$ in choosing over the features $s, t$, and $u$ when they are the features of the one proposed legal state in case $A$, since $s$ is the feature common to $L_{1}$ and $L_{2}$. However, in choosing over the features $s, t$, and $u$ when they are the chosen rationalizations, or rules, of several such cases (the cases $\mathrm{A}, \mathrm{B}$, and $\mathrm{C}$ ), we would choose feature $u$. Feature $u$ provides an overarching rationalization, or rule, for all of the three cases.

Thus, the final choice over all the chosen rules, each of which had originally rationalized one of the cases in the first partition, reduces to choosing rule $u$. But for analogous reasons, the final choice over all the rules that rationalized each of the cases in the second partition reduces to choosing rule $s$, or that feature common to the three cases C, D, and A. In this way, therefore, the final 
choice of an overarching rationalization of this set of like cases from the possible set $(r, s, t, u)$ of legal rules is completely dependent on the partitioning of these alternatives across the cases. It is therefore path dependent.

Someone might object that there is no surprise in this, and certainly no serious violation of any choice-consistency condition central to rational social choice theory. Surely we should expect different sets of cases to require different overarching rationalizations. But this objection ignores two things. First, within each set of cases, the same overall set of possible rules, or legal features, $(r$, $s, t, u)$ is available for choice. In other words, it is this unchanging set of rules, and not different sets of cases, that defines the choice set $\mathbf{S}$ in this situation and for which the usual choice-consistency conditions, arguably, should apply.

But perhaps the objection means to suggest not that the choice set $\mathrm{S}$ is changed under different sets of cases, but rather that the different cases change the nature of the social choice function $\mathbf{C ( S )}$ which operates on S. Surely no choice-consistency condition was ever meant to generate consistent choices over totally different social choice functions. But this version of the objection fares no better than the first, for it ignores the fact that if, from the same set $\mathrm{S}$ of four possible legal features or rules, we are trying always to choose one best overall rationalization for the same set of like cases, then we are at all times in search of the same social choice function. It just so happens that we do not rationalize (or rationalize the rationalizations for) the different case-based partitions of that choice set $\mathrm{S}$ in the same way. But then that is to accept path dependence in legal decision making, not object to it.

Still, despite these violations of choice theoretic rationality, ${ }^{80}$ and despite the diversity of reasons offered for the different case decisions (the thing that most bothered the legal skeptic), even the most casual glance at all the case decisions together in Figure 1 reveals that there is something systematic going on in this adjudicative sequence taken as a whole. It is easy to see that each case is similar to any other case in the matrix, although, again, not for the same reasons. Indeed, these cases share no one feature (or possible

${ }^{85}$ Three different violations of choice-theoretic rationality have now been presented: (i) a violation of the choice-consistency condition WARP, (ii) a violation of path independence, and (iii) a violation of the acyclicity requirement in the social preference relation. This suggests that the suspect property in rational social choice must be that property which all three of these rationality conditions share, namely, the contraction consistency property of inclusion. On this, see text accompanying notes 55-56. 
reason) in common. In Wittgenstein's terms, they are the stuff of "family resemblance" rather than definitive deduction. ${ }^{86}$

Note too that because all the cases are like one another, we have more than a mere chain of similarity here, more than, for example, some case $P$ that is similar to another case $Q$ (because they have two features in common), a case $Q$ similar to yet another case $R$ (because they have two features in common), but a case $R$ not at all similar to case $P$ (because they have few or no features in common). The relation "is similar to" is not a transitive relation. Thus, the chain of similarity that begins with $\mathrm{P}$ might end up with something completely different in $\mathrm{R}$. This would be an odd way to generate a class of "like cases," at least if the idea were that they should form some coherent whole. ${ }^{87}$

This last point is an important one for understanding the rationality of formal justice that might generate, for example, the matrix of like cases shown in Figure 1. Here there is also a chain of similarity judgments, linking, for example, case A to case B, case B to case $C$, and case $C$ to case $D$. But because that is not all there is, and because the relation "is similar to" is transitive here, so that case D is similar to case A (and, indeed, any other case in the set), we can be confident that there is more to formal justice than merely reasoned judgments of similarity between different subsets of the set of cases. The reasons are more disciplined than that, although not so disciplined that they manifest the rationality of deduction, that is, some common defining feature found in all the "like cases." The rationality of formal justice shows that the courts are up to something, and that it is the same something at the end of a chain of different similarity judgments as it was at the beginning. But it is not the sort of something that can be defined by a true universal that informs the major premise of a deduction ap-

Bs See Wittgenstein, Philosophical Investigations at $\$$ 65-67 (cited in note 70). The most famous passage, of course, is the one in which Wittgenstein asks his interlocutor to consider the category of "games":

What is common to them all?-Don't say: "There must be something common, or they would not be called 'games" "-but look and see whether there is anything common to all.-For if you look at them you will not see something that is common to all, but similarities, relationships, and a whole series of them at that. To repeat: don't think, but look!

Id at $\$ 66$. For an interesting discussion of Wittgenstein's notion of family resemblance, which comes very close to this Article's use of the idea, see Dennis Jay Packard, A Note on Wittgenstein and Cyclical Comparatives, 36 Analysis 37 (1975).

${ }^{87}$ Recall the difference between coherence and consistency as discussed in the text accompanying note 8 . Coherence involves some common project or enterprise. 
plied equally to all the cases. Nor, as we have seen, is it something rationalizable as maximization. ${ }^{88}$

Instead the common law is up to something that cannot be defined in terms of some set of necessary and sufficient characteristics of the social states available for choice. This insight may seem unhelpful, and it will appear particularly frustrating to be told that it is perfectly reasonable for the law to continue doing this "something," whatever it is, rather than attempt rationally to choose some more preferred social state. Surely, it will be suggested, the law can be both more definitive and more useful to us than this.

These are both reasonable objections and, doubtless, they call for a serious response. However, a full response would require that we attend to the large and very difficult question of what it is to properly justify a practice or activity to begin with, and what role is properly to be played by instrumental rationality, or rational choice, within such a justification. ${ }^{89}$ These are questions better left for another day and, perhaps, another author. The point of the analysis so far has only been to suggest that, given the structure of adjudication, it might be very difficult to provide legal reasoning with the purely instrumental justification envisaged by rational social choice theory.

However, this Article does attempt to move beyond this purely structural point to provide at least a partial response. The next Section uses an example from tort law to illustrate more concretely

${ }^{88}$ It has been observed in a wide range of literature that a diversity of reasons in different choice situations might be contrary to the logic of maximization. See, for example, the discussion of Aristotle's analysis of weakness of will in David Wiggins, Weakness of Will, Commensurability, and the Objects of Deliberation and Desire, in Amélie Oksenberg Rorty, ed, Essays on Aristotle's Ethics 241, 255-61 (California, 1980). In the quite different literature on the economic theory of social choice, see Schwartz, Collective Choice at 128 (cited in note 3). Both authors point to how easy it is, simply by reversing the relevant quantifiers, to confuse the rationality of providing $a$ reason for each choice with the maximization involved in always providing the same reason.

Compare the proposition that "for all choices over all pairs of alternatives $(m, n)$, there exists a reason $R$ such that $R$ is the reason for choosing between $m$ and $n$," with the proposition that "there exists a reason $R$ for all choices over all pairs of alternatives $(m, n)$ such that $\mathrm{R}$ is the reason for choosing between $m$ and $n$." While the former only indicates that there are reasons for all choices, reasons that may be coherently related, the latter indicates that the same reason explains all choices. In social choice theory, this single (maximizing) reason masquerades as a "social utility (or welfare) function" or, more generally (and somewhat more weakly), as a social ordering. This point is closely related to the one made about pluralism and incommensurability in the text accompanying note 47.

${ }^{89}$ For an account of what constitutes a proper justification of a legal practice, see Ernest J. Weinrib, Formalism and its Canadian Critics, in Ken Cooper-Stevenson and Elaine Gibson, eds, Tort Theory 6, 8-13 (Captus, 1993). 
the rather abstract account of adjudication that has so far been provided in this Section. By furnishing a specific context for the construction of a coherent set of like cases, we should be able to get a better sense of what might be meant by the elusive (because indefinable) "something" that forms the focus of such a set. Section IV addresses the concern that it seems manifestly unreasonable to carry on doing something we have always done just because we have done it once; surely, we can do better. My claim there is that some real good can come from this constant reinforcement of the past, perhaps even the sort of good that the rational choice theorist herself might most want to achieve. Ironically, however, this good may most likely be attained if the law is not used as an instrument for the good's rational and self-conscious pursuit.

\section{AN EXAMPLe From TORT LAW}

The preceding discussion of the nature of rationality in adjudication has been very abstract. A concrete example would buttress the argument. The following discussion of tort law developments shows how some of the important decisions of the high courts of the United Kingdom, decisions that deal with the problematic questions of duty and remoteness, might be rationalized as a coherent set of like cases.

\section{A. Privity, Foreseeability, and Directness}

Just as for the abstract example developed above, the analysis here begins with a legal status quo, $\mathrm{L}_{1}$. Specifically, it is the status quo before the famous case of Donoghue $v$ Stevenson, ${ }^{90}$ the first of our four cases (case A), and the case that will transform $L_{1}$ into $L_{2}$, a legal state defined by a different legal feature. The status quo $\mathrm{L}_{1}$, as Donoghue makes clear, was a legal state defined by the following rule, which, consistent with earlier notation, we represent as rule $r$.

${ }^{90}$ [1932] App Cas 562 (HL 1932). In this case, an individual bought a bottle of ginger beer for a friend who, on drinking the contents of the bottle, allegedly discovered the remains of a decomposed snail in it and suffered damages as a result. The friend sued the manufacturer of the ginger beer, even though there was no contract between her and the defendant. Despite this lack of privity, however, the House of Lords held that the manufacturer owed her a duty of care as a third party for whom it could reasonably be foreseen that harm might ensue as a result of the negligent conduct. Id at 599. In the United States, the "no privity" rule had already been replaced by foreseeability. See, for example, MacPherson v Buick Motor Co., 217 NY 382, 111 NE 1050 (1916). 
Rule $r$ : When there is a contractual relationship, no plaintiff can sue to recover for consequential damages flowing from the breach of that contractual relationship unless she is a party to the contract.

Rule $r$, of course, is the well-known "privity" rule from Winterbottom $v$ Wright, ${ }^{91}$ which, on some interpretations at least, was overturned by Donoghue. However, as we shall soon see, Winterbottom, far from being overturned and left behind by Donoghue, is actually quite coherent with it. This will become apparent once the cycle of "like cases" has been completed and we see that the rule in Winterbottom has reappeared in only slightly different form in some more recent tort cases.

The rule in Donoghue emphasizes foreseeability rather than privity as the source of duty in tort law. We represent the foreseeability rule here as rule $s$.

Rule $s$ : A defendant is prima facie ${ }^{92}$ liable for damage directly caused to the plaintiff if and only if she has been negligent in her conduct as measured by the standard of a reasonable person, her negligence is a cause of the plaintiff's injury, ${ }^{93}$ and some injury to the plaintiff, given this negligent conduct, was reasonably foreseeable. ${ }^{94}$

${ }^{92}$ [1843] $152 \mathrm{ER} 402$ (Ex Ch 1842). Here a driver for the postal service was injured by a defective postal coach and sued a defendant whom the postal service had hired to keep the coaches in good repair. The suit failed because the driver was not a party to the repair contract, that is, he lacked "privity."

${ }^{82}$ The defendant is only prima facie liable because certain defenses (for example, voluntary assumption of the risk) may still be available.

${ }^{83}$ This need not mean a "but for" cause. For a good discussion of the problems confronted by tort law in providing an adequate account of causation, see the pieces in Symposium on Causation in the Law of Torts, 63 Chi Kent L Rev 397-680 (1987).

94 The discerning reader will recognize that this articulation of the rule in Donoghue still includes part of the rule employed to hold the defendant liable In re Polemis and Furness, Withy \& Co. Ltd., [1921] 3 KB 560 (CA 1921). In Polemis, the English Court of Appeal held that a defendant could be liable for all the "direct" consequences flowing from her negligent act even if those consequences were not foreseeable. Id at 574. In other words, foreseeability of damage was material in determining whether the defendant was negligent, but foreseeability did not act as a limitation on the sorts of damages that were recoverable (either what type or by whom) from a defendant. In Donoghue, the House of Lords effectively narrowed the "directness" rule in Polemis to apply only to those plaintiffs for whom it could be reasonably foreseen that harm might ensue as a result of the defendant's negligence. The oddity of having the directness rule without the Donoghue limitation is nicely illustrated by the case $F$. W. Jeffrey and Sons Ltd. and Finlayson $v$ Copeland Flour Mills, [1923] 4 DLR 1140 (Ont 1923) (allowing an unforeseeable plaintiff to recover for an injury directly caused by a breach of a duty of care owed to another whose injury would have been foreseeable). As will be seen, it took a further case to correct the oddity still latent in the 
The last clause emphasizing foreseeability is the operative part of the rule for our purposes since it is this part that broadens the duty beyond the privity rule $r$ announced in Winterbottom. However, because the House of Lords in Donoghue felt obliged to address Winterbottom as a case on point, ${ }^{95}$ and one of the law lords even felt obliged to follow it in his dissent, ${ }^{96}$ it seems reasonable to characterize both cases as sharing foreseeability as a legal feature even though only Donoghue raises this feature to the status of an announced rule. Thus, Winterbottom is characterized by both legal features $r$ and $s$, but is defined by the feature $r$ as the rule governing the case. Donoghue, on the other hand, rejects feature $r$ even as a characterizing feature of the new legal state $L_{2}$ (rejects $r$ as "bad law") and elevates feature $s$ to the status of a defining rule for $\mathrm{L}_{2}$. We are now well on our way to a reconstruction of the matrix shown in Figure 1.

\section{B. Foreseeability and the Type of Damage}

Consider now the facts of another prominent case in this area, Overseas Tankship (U.K.) Ltd. v Morts Dock and Engineering Co. Ltd., ${ }^{97}$ usually called The Wagon Mound (No. 1). ${ }^{98}$ In this case, some careless employees of the charterer of a ship had spilled some oil into Sidney harbor. The oil floated over to the plaintiff's dock where some repair work was being done. Two days later, some drops of molten metal falling from a welding operation on the dock ignited the floating oil. The resulting fire damaged the dock and the two ships moored there. The trial judge found as a fact that, although some damage to the dock was foreseeable, specifically the fouling of the dock's slipways by the oil, it was not reasonably foreseeable that the oil would catch fire on the water and burn the dock.

Although Wagon Mound did not explicitly reject the ruling in Donoghue, it did make a fundamental adjustment to the rule $s$ articulated in Donoghue. The Privy Council found that, although the defendant's negligence had been a direct cause of the injury suffered by the plaintiff, and despite the fact that the defendant owed

Donoghue rule allowing a foreseeable plaintiff to recover all direct damages even though some were unforeseeable. See text following note 98 .

${ }^{95}$ [1932] App Cas at 588-89, 592 (Lord Atkin).

96 Id at 568 (Lord Buckmaster).

${ }^{97}$ [1961] App Cas 388 (PC 1961).

98 The case takes its name from the ship that appears in it, and is to be distinguished from The Wagon Mound (No. 2), [1966] 2 All ER 709 (PC 1966), a different litigation stemming from the same misadventure. 
a duty not to spill oil into the harbor (because it was foreseeable that such spillage would do harm to the plaintiff), the defendant was not liable to the plaintiff for any damage done by the fire because that type of damage was not foreseeable. Thus, Wagon Mound, case B in our Figure 1 matrix, effectively rejected rule $s$ and substituted the following rule $t$ as the defining rule for a new legal state $\mathrm{L}_{3}$.

Rule $t$ : A defendant is prima facie liable for damage caused to the plaintiff if and only if she has been negligent in her conduct as measured by the standard of a reasonable person, her negligence is a cause of the plaintiff's injury, and the injury to the plaintiff was of the type that, given the negligent conduct, was reasonably foreseeable.

Now, as already suggested, in articulating rule $t$ in Wagon Mound, the Privy Council did not actually see itself as overturning any understanding of the foreseeability rule in Donoghue. Thus, it might be thought that legal state $L_{3}$, defined by rule $t$ in Wagon Mound, or case B of our matrix, should not be characterized as a legal state bereft of legal feature $s$. It might be suggested, for example, that $\mathrm{L}_{3}$ would be better seen as a legal state still characterized by legal feature $s$, only with feature $t$ rather than $s$ elevated to the status of the defining rule. However, in Wagon Mound, the Privy Council did explicitly reject all of the directness aspects of the rule offered In re Polemis, ${ }^{99}$ a rule broader than rule $s$ (which limits the application of the directness test to foreseeable plaintiffs). Thus, rejecting all the directness aspects of the rule in Polemis in asserting the new rule $t$ is a fortiori a rejection of rule $s$ (foreseeability plus directness).

The three legal features $r, s$, and $t$ that characterize legal state $\mathrm{L}_{1}$ in the matrix of Figure 1 have now been given content in the context of the three leading cases Winterbottom, Donoghue, and Wagon Mound-all cases that attempted to articulate a rule regarding the relationship required between the defendant (or the

\footnotetext{
sa See note 94 .
}

Enough has been said to show that the authority of Polemis has been severely shaken though lip-service has from time to time been paid for it. In their Lordships' opinion it should no longer be regarded as good law. . . . For it does not seem consonant with current ideas of justice or morality that for an act of negligence, however slight or venial, which results in some trivial foreseeable damage the actor should be liable for all consequences however unforeseeable and however grave, so long as they can be said to be "direct."

Wagon Mound, [1961] App Cas at 422. 
defendant's conduct) and the plaintiff (or the plaintiff's injury) so as to support liability. It has also been suggested that while legal feature $r$ in $\mathrm{L}_{1}$ is uniquely elevated to the status of a rule in that legal state, the other legal feature $s$, or foreseeability of the plaintiff, must also have been present in $L_{1}$ if Winterbottom was correctly thought to have been on point in Donoghue. But what about legal feature $t$ ? Was this feature present in $L_{1}$ and $L_{2}$ in the same characterizing way as the matrix in Figure 1 suggests? And if it was, why was it not the basis for a rule defining those legal states in the same way that it was in $\mathrm{L}_{3}$ ?

It seems clear in both Winterbottom and Donoghue that, given the negligent conduct of the defendant, the type of injury that the plaintiff actually suffered was reasonably foreseeable. Thus, legal feature $t$ was present in $\mathrm{L}_{1}$ and $\mathrm{L}_{2}$. After all, both cases involved products intended for use by ultimate consumers and both of the plaintiff/consumers in these cases used the products exactly as intended. Moreover, the type of injury sustained by each plaintiff was exactly the sort of injury one would expect to result from normal use of the different products, given that each was defective in the way described in the cases' facts. Thus, defective products (for defective read "dangerous when used normally") in these cases would foreseeably expose the plaintiffs to exactly the type of injury that occurred. But why was this characterizing feature not elevated by these cases to the status of a legal rule defining the legal states? Why did this happen only in Wagon Mound? The answer, of course, is that the facts of the cases effecting the change to legal states $L_{1}$ and $L_{2}$ did not force any special consideration of "type of damage," and so did not require that legal feature $t$ be raised to the status of a defining rule. In short, it was precisely because the plaintiffs in these cases had so obviously suffered the type of injury that was foreseeable that there was no salience to that fact, and thus no need to address the issue with a rule.

So now we have an account of all the characterizing features of the status quo legal state $L_{1}$, together with a claim that one of those features, namely $r$, was elevated to the status of a rule in Winterbottom. Exactly why this legal feature $r$ became so salient and assumed the status of a rule will have to await completion of our analysis of the cycle of "like cases." Unlike more linear, instrumental analyses of the law, in the coherence analysis of formal justice presented here, the best possible understanding of "the beginning" (and this is already too linear a word), or the status quo legal state, can only be had through examining the whole. And, as we 
shall see, this better understanding of the beginning will require us to rearticulate rule $r$.

We also have an account of two of the characterizing features of $\mathrm{L}_{2}$, namely $s$ and $t$. But nothing yet has been said about the third characterizing feature of $\mathrm{L}_{2}$, legal feature $u$, the only feature of the legal states in Figure 1 that has not yet been discussed. Indeed, we have still to identify what we mean by this feature, let alone say why it is a legal feature of any of the legal states defined by these cases. We therefore turn to a discussion of the meaning and importance of legal feature $u$.

\section{Foreseeability and the Probability of Damage}

The most natural way to get some understanding of legal feature $u$ is to consider how Wagon Mound's rule $t$ was inadequate, and thus induced the House of Lords to raise the new legal feature $u$ to the status of a rule in the case of Home Office $v$ Dorset Yacht Co., $L t d .{ }^{100}$ This case transforms legal state $\mathrm{L}_{3}$ to legal state $\mathrm{L}_{4}$, and represents case $\mathrm{C}$ in the Figure 1 matrix.

In Dorset Yacht, seven convicted juveniles attempted to escape the custody of the defendant during a training excursion to an island. In the course of their escape, they caused a yacht to collide with the plaintiff's yacht, which was moored in the vicinity. The plaintiff sued the defendant Home Office for the damage to his yacht. The House of Lords found as a fact that the defendant had been negligent in its supervision of the juveniles and, therefore, allowed the plaintiff to recover. ${ }^{101}$ However, on the way to this result the law lords had to struggle with the fact that the damage had actually been caused by a third party, the escaping juveniles. The question was whether this conduct by a third party was sufficient to break the chain of causation linking the defendant's wrongdoing to the plaintiff's injury. ${ }^{102}$ In other words, at issue again was the nature of the requisite relationship between the parties or, more accurately, between one party's conduct and the other party's injury, if there was to be liability.

Lord Reid, who wrote the judgment of the majority, emphasized the strong likelihood, given negligent supervision of juveniles on an island, that these juveniles would attempt to effect their escape on a boat and damage other boats in the process. ${ }^{103}$ Of course,

200 [1970] 2 All ER 294 (HL 1970).

101 Id at $297,302$.

102 Id at 298-300.

103 Id at 300-01. 
it is also foreseeable that, having escaped, these juveniles might return to a life of crime and damage other property far from the scene of the escape. But the law lords took pains to emphasize that plaintiffs in this latter situation would have no right of recovery. Lord Reid held that it was the higher "degree of probability" of the former kind of injury that made it the "natural and probable result" of the defendant's conduct and, therefore, preserved the causal relationship between the parties. ${ }^{104}$ This causal link would not be in place if the plaintiff had merely suffered injury because the escapees had returned to crime; while foreseeable, that was not "very likely to happen."105 rule $u$.

Thus, we have in Lord Reid's judgment yet another rule,

Rule $u$ : A defendant is prima facie liable for damage caused to the plaintiff if and only if she has been negligent in her conduct as measured by the standard of a reasonable person, her negligence is a cause of the plaintiff's injury, and the injury to the plaintiff was reasonably foreseeable, given the negligent conduct. However, if a third party's conduct forms one of the causal links between the defendant's negligence and the plaintiff's injury, then this conduct must not only be foreseeable, it must also be highly probable.

That rule $u$ in Dorset Yacht represents a denial of the rule $t$ announced in Wagon Mound, and not just some minor adjustment in emphasis necessitated by new facts, can be better appreciated if we let the majority judgments in the two cases speak for themselves. In Wagon Mound, Viscount Simonds dismisses the idea that "probable" consequences could have any more relevance per se than merely foreseeable consequences:

For, if it is asked why a man should be responsible for the natural or necessary or probable consequences of his act (or any other similar description of them) the answer is that it is not because they are natural or necessary or probable, but because, since they have this quality, it is judged by the standard of the reasonable man that he ought to have foreseen them. Thus it is that over and over again it has happened that in different judgments in the same case, and sometimes in a single judgment, liability for a consequence has been imposed 
on the ground that it was reasonably foreseeable or, alternatively, on the ground that it was natural or necessary or probable. The two grounds have been treated as coterminous, and so they largely are. ${ }^{106}$

Thus, according to Viscount Simonds, considering what might be "probable" is not a mistake; rather his point is only that such considerations have no special or independent standing in law. Their only legal relevance is under the aspect of what is "foreseeable." Hence, the latter feature, and not the former, is elevated to the status of a rule in his Wagon Mound judgment.

Of course, if the two grounds of "probability" and "foreseeability" were really coterminous, as Viscount Simonds suggests, then Lord Reid would not have needed to provide for the new rule $u$ in Dorset Yacht. After reviewing some of the cases involving conduct by third parties, Lord Reid put the point as follows:

What then is the dividing line? Is it foreseeability or is it such a degree of probability as warrants the conclusion that the intervening human conduct was the natural and probable result of what preceded it?

..

.. These cases show that, where human action forms one of the links between the original wrongdoing of the defendant and the loss suffered by the plaintiff, that action must at least have been something very likely to happen if it is not to be regarded as novus actus interveniens breaking the chain of causation. I do not think that a mere foreseeable possibility is or should be sufficient . . . . 107

Clearly, then, "the probable" does not just stand in for the "the foreseeable" when the latter cannot be judged directly. Rather, according to Lord Reid, the probable adds a whole new consideration to our understanding of the proper relation that must exist be-

${ }^{108}$ [1961] App Cas at 423.

${ }_{107}$ [1970] 2 All ER at 298-300. Note that, as expressed here, the rule in Dorset Yacht goes beyond the intervening conduct of third parties. The phrase "where one of the links is some human action" could easily embrace the intervening conduct of the plaintiff, such as when the plaintiff in Donoghue chose to drink the ginger beer. Presumably, under Lord Reid's interpretation of the cases, the foreseeability of this last event would no longer be enough to ground liability; the event would also have to be "very likely to happen" and, for that reason, would be foreseeable. Thus, in Dorset Yacht, the degree of probability is the independent determining factor for tortious liability, and foreseeability is reduced to a merely evidentiary role for suggesting that this factor is in place. This, of course, is the exact opposite of the relationship between foreseeability and probability suggested by Viscount Simonds in Wagon Mound. 
tween the defendant's conduct and the plaintiff's injury if there is to be liability. Thus, where Wagon Mound can tolerate legal feature $u$ as a characterizing feature of legal state $L_{3}$, even though it does not raise it to the status of a salient legal rule, Dorset Yacht, at leást under Lord Reid's majority judgment, must reject what Wagon Mound does elevate to that status, namely legal feature $t$, and substitute feature $u$ as the rule instead.

This discussion also allows us to say something now about the characterizing role played by legal feature $u$ in legal state $L_{2}$ as selected by our case A, Donoghue. Donoghue, we have seen, incorporates a restricted version of the directness rule used in Polemis and rejected once and for all in Wagon Mound. Interestingly, the seeds of Lord Reid's final invocation of the "probability" rule $u$ are already in place in Polemis and, by implication therefore, in Donoghue. In Polemis, Lord Justice Scrutton weighs the relevance of considering the probable (rather than the direct) consequences of the defendant's conduct. In contrast both to Viscount Simonds, who admits that what is probable might be some evidence for what is foreseeable, and to Lord Reid, who argues that what is probable has such independent and legally salient standing as to be incorporated into a rule, Lord Justice Scrutton simply thinks it unhelpful to focus on what is probable:

On this head we were referred to a number of well known cases in which vague language, which I cannot think to be really helpful, has been used .. . I cannot think it useful to say the damage must be the natural and probable result. This suggests that there are results which are natural but not probable, and other results which are probable but not natural. I am not sure what either adjective means in this connection; if they mean the same thing, two need not be used; if they mean different things, the difference between them should be defined. And as to many cases of fact in which the distinction has been drawn, it is difficult to see why one case should be decided one way and one another. ${ }^{108}$

Thus, while in legal state $\mathrm{L}_{2}$ under case $\mathrm{A}$ in Figure 1 , considerations involving what is probable, or legal feature $u$, are only "unhelpful," by the time these considerations reach legal state $\mathrm{L}_{3}$ under case $B$, such considerations are evidence of what is really legally salient under the "foreseeable type of damage" rule, rule $t$. Finally, in legal state $\mathrm{L}_{4}$ under case $\mathrm{C}$, considering the probable 
consequences of the defendant's act has assumed the status of a legal rule, namely rule $u$.

This might seem to complete the account of legal feature $u$ since it does not appear in legal state $L_{1}$, now defined by case $D$ in our matrix. But this is too quick. Case $D$, described in the next Subsection, attempts to define a legal state with the rule $r$, and without legal feature $u$ even playing the unhelpful characterizing role it played in legal state $\mathrm{L}_{2}$ : This is a strong denial of feature $u$, and it requires an explanation. As we shall now see, and might now expect, the explanation for the strong denial of Lord Reid's rule $u$ in case $\mathrm{D}$ is closely related to the reassertion of legal feature $r$ as a legal rule, something the more linear-maximizing instrumentalist might have thought we permanently left behind in case $A$.

\section{Foreseeability and Proximate Relation: The Privity Rule Reconsidered}

Case D in the Figure 1 matrix will represent the recent House of Lords case Caparo Industries Plc. $v$ Dickman. ${ }^{109}$ In this case, the plaintiff, contemplating a takeover of a target company, had purchased shares in the company in apparent reliance on an audit of financial statements that the defendant auditing company had performed for the target company. After the successful takeover attempt, the plaintiff discovered that the target company was in worse financial shape than expected, and that the takeover bid had been too high. The plaintiff attributed its mistaken bid to the defendant's negligent failure to detect the misrepresentation in their audit. The plaintiff therefore sued to recover its economic loss. ${ }^{110}$

While the Court of Appeal held that the defendant was liable for breaching a duty of care owed to the plaintiff as a shareholder, ${ }^{111}$ the House of Lords reversed this decision, arguing that information and advice in general, and auditing services in particular, are provided with a particular purpose in mind, and that liability for negligence must be restricted to foreseeable losses from the use of information for that particular purpose. ${ }^{112}$ The House of Lords opined that the Companies Act ${ }^{113}$ indicated that the finan-

109 [1990] 2 WLR 358 (HL 1990).

110 Id at 361-62.

${ }^{111}$ Caparo Industries Plc. v Dickman, [1989] 2 WLR 316 (CA 1989).

112 Caparo, [1990] 2 WLR at 367-68.

113 The Companies Act 1985, 1985 CLSA (UK), ch 6, was in force when the facts in Caparo arose. The relevant provisions in that Act were $\$ \S 236-41,246$, and 384. These provisions have been amended by the Companies Act 1989, 1989 CLSA (UK), ch 40, §§ 9-11, 13 , and 119. 
cial statements in Caparo had primarily been prepared for the use of the target company's shareholders at their annual meeting and not for the purpose of an outside investor launching a takeover, no matter how foreseeable. ${ }^{114}$ And since the plaintiff had not used the negligently audited financial statements for their intended purpose, there was no liability.

In Caparo, the plaintiff/investor had tried to generate liability by emphasizing that the target company was vulnerable and a takeover was very likely, ${ }^{115}$ precisely the criteria emphasized by Lord Reid in Dorset Yacht. But Lord Bridge was explicit in his rejection of these submissions:

I should . . . be extremely reluctant to hold that the question whether or not an auditor owes a duty of care to an investor buying shares in a public company depends on the degree of probability that the shares will prove attractive either en bloc to a take-over bidder or piecemeal to individual investors. It would be equally wrong, in my opinion, to hold an auditor under a duty of care to anyone who might lend money to a company by reason only that it was foreseeable as highly probable that the company would borrow money at some time in the year following publication of its audited accounts and that lenders might rely on those accounts in deciding to lend. I am content to assume the high probability of a take-over bid . . . but I do not think it assists [the plaintiffs'] case. ${ }^{116}$

Thus, it seems clear that the legal state $L_{1}$, which Caparo brought into being out of legal state $L_{4}$, cannot be characterized with legal feature $u$, the feature that had proved so decisive for Lord Reid in Dorset Yacht. Despite the high probability of the very injury that occurred, there was no liability for that injury in Caparo.

What about legal features $s$ and $t$, which emphasize, respectively, the foreseeability of the plaintiff and the foreseeability of the type of injury suffered? It might seem that Caparo goes some way toward rejecting these as possible characterizing legal features for $\mathrm{L}_{1}$ as well. After all, despite the presence of negligence causing a foreseeable type of loss to a foreseeable plaintiff, there was no liability. Yet, both the legal features $s$ and $t$ continue to appear as characterizing features of legal state $L_{1}$ in Figure 1 . It might seem terribly ad hoc (and very convenient for the "like cases" analysis

114 Caparo, [1990] 2 WLR at 372-73.

115 Id at 370.

${ }^{118} \mathrm{Id}$ at 371. 
that is being tested here!) to drop feature $u$ in $\mathrm{L}_{1}$ after Caparo and yet hang on to features $s$ and $t$.

However, in the absence of the peculiarly quantitative concern that goes with seeing foreseeability as "degree of probability" under feature $u$, one can now see the concerns for foreseeability, which first surfaced in the form of the rule $s$ in Donoghue (and which were conjoined there with feature $u$, just as rule $t$ was in Wagon Mound), in a quite different light. Specifically, without feature $u$ to help characterize them in a probabilistic way, the law lords gave the foreseeability concerns $s$ and $t$ a "relational" interpretation in Caparo. Consider, for example, the following (somewhat long-winded) remarks by Lord Oliver:

The question is, I think, one of some importance when one comes to consider the existence of that essential relationship between the appellants and the respondent to which, in any discussion of the ingredients of the tort of negligence, there is accorded the description "proximity," for it is now clear from a series of decisions in this House that. . . the duty of care in tort depends not solely upon the existence of the essential ingredient of the foreseeability of damage to the plaintiff but upon its coincidence with a further ingredient to which has been attached the label "proximity" and which was described by Lord Atkin in the course of his speech in Donoghue v. Stevenson as:

such close and direct relations that the act complained of directly affects a person whom the person alleged to be bound to take care would know would be directly affected by his careless act. ${ }^{117}$

From these remarks, it is clear that, for there to be liability, a relationship of proximity must at least coincide with concerns for foreseeability as a characterizing legal feature of $\mathrm{L}_{1}$, the legal state chosen by Caparo, or case $\mathrm{D}$ in the Figure 1 matrix. As a result, foreseeability of the plaintiff and the type of damage is not so much displaced by the relational concerns of proximity in Caparo as "supplemented" or "recharacterized" by them. We are therefore justified in keeping features $s$ and $t$ as characterizing legal features of $\mathrm{L}_{1}$ in Figure 1 even though legal feature $u$ can no longer play such a role.

We should now try to articulate the rule $r$, which, according to the matrix in Figure 1 , is the rule defining legal state $L_{1}$ after case

117 Id at 378, quoting Donoghue, [1932] App Cas at 581 (Lord Atkin). 
D or Caparo. Rule $r$, of course, we have already characterized above as the "privity rule" of Winterbottom, the rule allegedly overturned by the foreseeability rule in Donoghue. Is there any real sense in which we have returned to the privity rule in Caparo simply because we have supplemented foreseeability with an additional test of proximity? This seems implausible, since there is in theory no reason to equate what is meant by proximity in Caparo with what we typically understood as privity in contract.

However, being in privity is one way of being proximate and, therefore, a denial of proximity would amount to (among other things) a denial of privity. A common fallacy is to reverse this implication, suggesting instead that a denial of privity is a denial of proximity. ${ }^{118}$ Could this have been what the Court of Exchequer did in Winterbottom? Could it be that, in applying a proximity test, the Court reasoned that because the plaintiff was not in privity with the defendant, there was not sufficient proximity in their relationship to find tortious liability? That, too, seems implausible, but there is nevertheless a clue in it. The truth of the matter is that the plaintiff in Winterbottom never presented any evidence that would have established a relationship of proximity between himself and the defendant. The plaintiff asserted only that the defendant had breached his contract with a third party, a fact which, even if proved true, could do nothing to establish the needed relationship of proximity between the litigating parties. ${ }^{119}$ Without further evidence to go on, the Court of Exchequer was quite right to deny liability to the plaintiff for breach of contract in the absence of privity. But the denial was effectively a denial of liability

118 This type of fallacy is often referred to as "affirming the consequent." See, for example, Henry C. Byerly, A Primer of Logic 41-42 (Harper \& Row, 1973).

119 In referring to Winterbottom in Donoghue, Lord Atkin wrote:

It is to be observed that no negligence apart from breach of contract was alleged-in other words, no duty was alleged other than the duty arising out of the contract; it is not stated that the defendant knew, or ought to have known, of the latent defect. The argument of the defendant was that, on the face of the declaration, the wrong arose merely out of the breach of a contract, and that only a party to the contract could sue. The Court of the Exchequer adopted that view, as clearly appears from the judgments of Alderson and Rolfe BB. There are dicta by Lord Abinger which are too wide as to an action of negligence being confined to cases of breach of a public duty. The actual decision appears to have been manifestly right . . . .

Donoghue, [1932] App Cas at 589. Lord MacMillan made similar comments; see id at 60810. The rule articulated by Lord Abinger (rule $r$ as it appears in text accompanying note 90), that was "too wide" in its exclusion of actions for negligence in the presence of contract, was, unfortunately, the one that caught on as a matter of judicial interpretation and eventually needed correction in Donoghue. It is arguable, however, that all of the opinions in Winterbottom come close to the Abinger rule. 
in contract (since that was all the plaintiff argued), not a denial of the possibility of tort liability on the same facts in the presence of that contract, the sort of thing articulated by rule $r$.

This suggests that we should now characterize rule $r$ somewhat differently. (Call it rule $r^{*}$ to remind us that, although it too generates the Winterbottom result, it is a recharacterization, or new understanding, of the rule $r$ in light of more recent cases.)

Rule $r^{*}$ : A defendant is prima facie liable for damage caused to the plaintiff if and only if she has been negligent in her conduct as measured by the standard of a reasonable person, her negligence is a proximate cause of the plaintiff's injury, and the injury to the plaintiff was of the type that, given the negligent conduct, was reasonably foreseeable.

All that rule $r^{*}$ adds to rule $t$, as used in the Wagon Mound, is the word "proximate," which stands in for the new concern for relational proximity between the defendant and the plaintiff. This was the concern the plaintiff in Winterbottom never addressed, turning his attention instead to a (contractual) relationship between the defendant and some other party. The legal feature $u$ that had proved so salient for Lord Reid in Dorset Yacht has been abandoned completely in rule $r^{*}$, but the foreseeability concerns captured by legal features $s$ and $t$ have been preserved.

In all of this shuffle, one might reasonably wonder what has happened to the "particular purpose" test that the House of Lords actually used in Caparo to limit the defendant auditor's liability. Does rule $r^{*}$ capture any part of this concern? Should it not be a more explicit component of the rule? According to Caparo, the particular purpose test is only one way, albeit a commonly used way in cases of negligent misstatement, of characterizing the proximate relation that must exist between the defendant and the plaintiff before there can be tortious liability. Consider, for example, the following general remarks by Lord Oliver:

[T] he postulate of a simple duty to avoid any harm that is, with hindsight, reasonably capable of being foreseen becomes untenable without the imposition of some intelligible limits to keep the law of negligence within the bounds of common sense and practicality. Those limits have been found by the requirement of what has been called a "relationship of proximity" between plaintiff and defendant .... But although the cases in which the courts have imposed or withheld liability are capable of approximate categorization, one looks in vain for some common denominator by which the existence of 
the essential relationship can be tested. . . . "Proximity" is, no doubt, a convenient expression so long as it is realized that it is no more than a label which embraces not a definable concept but merely a description of circumstances from which, pragmatically, the courts conclude that a duty of care exists. ... I think that it has to be recognized that to search for any single formula which will serve as a general test of liability is to pursue a will-o'-the wisp. The fact is that once one discards, as it is now clear that one must, the concept of foreseeability of harm as the single exclusive test-even a prima facie test - of the existence of the duty of care, the attempt to state some general principle which will determine liability in an infinite variety of circumstances serves not to clarify the law but merely to bedevil its development in a way which corresponds with practicality and common sense. ${ }^{120}$

With this general caveat in mind, Lord Oliver then considers what might be said more specifically about the rules governing cases that, like Caparo, involve negligent misstatement:

[E]ven within the limited category of what, for the sake of convenience, I may refer to as "the negligent statement cases," circumstances may differ infinitely and, in a swiftly developing field of law, there can be no necessary assumption that those features which have served in one case to create the relationship between the plaintiff and the defendant on which liability depends will necessarily be determinative of liability in the different circumstances of another case.

...

... What can be deduced from the Hedley Byrne case $\left.{ }^{121}\right]$ is that the necessary relationship between the maker of a statement or giver of advice ("the adviser") and the recipient who acts in reliance upon it ("the advisee") may typically be held to exist where [among other things] the advice is required for a purpose, whether particularly specified or generally described, which is made known, either actually or inferentially, to the adviser at the time when the advice is given $\ldots .^{122}$

But Lord Oliver is careful to add immediately that the same general caveat applies. Namely, the purpose test and the other condi-

${ }^{120}$ Caparo, [1990] 2 WLR at 379.

${ }^{121}$ Hedley Byrne \& Co., Ltd. v Heller \& Partners, Ltd., [1964] AC 465 (HL 1964) (footnote not in original). This is the leading English case in the area of negligent misstatement.

${ }^{122}$ Caparo, [1990] 2 WLR at 381, 383-84. 
tions listed in cases involving negligent misstatement are not to be read as a definition of, or rule for, the proximity requirement, even in this more narrow area of tort law: "That is not, of course, to suggest that these conditions are either conclusive or exclusive, but merely that the actual decision in the case does not warrant any broader propositions."123 Thus, it would be a mistake to elevate the purpose test to the status of a defining rule in Caparo, which explains why it is not explicitly mentioned in the proximate-relation rule $r^{*}$ articulated above. ${ }^{124}$

However, the legal skeptic will now ask if there is really anything definitive to the proximate relation rule because it seems, at least in Lord Oliver's account, to comprehend a myriad of indefinable and wholly disparate elements, of which the "particular purpose" test in Caparo is only one. Does not such a broad rule simply obscure the fact that the courts have the discretion to do pretty much what they want under its guise? Would it not be better to state explicitly what goal the courts are attempting to achieve, in the way that the maximization model of rational choice would require (that is, put the goal, and the politics of selecting it, up front), and give up the charade that the tests of the proximity rule, such as the particular purpose test in Caparo, are actually constructed out of a disciplining set of "like cases"?

Such questions reveal the sort of uncharitable reading of the cases that is generated by the sense of frustration one must feel when one looks for the logic of deduction where it is not to be found. Moreover, the questions presuppose a correspondingly nar-

${ }^{123}$ Id at 384.

124 At one point, Lord Oliver comes close to elevating the purpose test to the status of a more general rule applicable to a much broader range of cases than just those similar to Caparo. He writes:

Before it can be concluded that the duty is imposed to protect the recipient against harm which he suffers by reason of the particular use that he chooses to make of the information which he receives, one must, I think, first ascertain the purpose for which the information is required to be given. Indeed the paradigmatic Donoghue v. Stevenson case of a manufactured article requires, as an essential ingredient of liability, that the article has been used by the consumer in the manner in which it was intended to be used.

Id at 397 (citations omitted). However, seen as a rule in this way, the purpose test seems wrong and in need of precisely the correction provided by rule $s$ in our less restrictive interpretation of Donoghue. The manufacturer of a product, or even the manufacturer and the buyer of the product in their contract, might have intended that the product be used in some particular way, but if the final consumer uses it in a reasonably foreseeable way, and is injured thereby, there may be liability. Caparo therefore holds, as these remarks of Lord Oliver suggest, the seeds of the narrow privity rule $r$ that had been used earlier to explain Winterbottom, and thus the possibility of setting off again on the cycle of "like cases." 
row view of the purpose test in Caparo. For, more broadly interpreted, it is clear that some attention to the purpose of good conduct, such as the purpose of an audit like the one in Caparo when it is performed non-negligently, must already be present in even the most run-of-the-mill tort case. ${ }^{125}$

For example, consider a motorist $A$, who has been speeding and has an accident with another motorist $B$, who pulled out in front of him without looking. Motorist B, who has been seriously injured, points to the speeding of $A$ as a negligent cause of the accident. Motorist $\mathrm{A}$ admits to the speeding, but argues that it is not causally relevant to the accident since the accident would have occurred even if A had been driving properly; even a driver going at a reasonable speed would not have been able to stop in time to avoid the collision. In other words, A admits his negligent behavior but disputes the cause-in-fact connection between this behavior and the plaintiff's injury. Thus, A says, there should be no tort liability. But consider B's next argument: B maintains that A's speeding is a cause-in-fact of the accident, because if A had not been speeding, A would not have been where he was at the particular time that B pulled out. ${ }^{126}$ In other words, "but for" the speeding, the accident would not have occurred. Thus, B argues that she can show all the constituent elements of a successful negligence action, namely, a duty owed to her as a foreseeable plaintiff, negligent behavior by the defendant in violation of that duty, and a very direct cause-in-fact connection between the defendant's negligent behavior and an injury of foreseeable kind suffered by her.

While, strictly speaking, there is something correct about B's argument, it is also slightly bizarre. Although $\mathrm{B}$ presents all the elements of negligence, they are not coherent. Moreover, we can see this incoherence quite clearly if we think about the purpose of driving safely, of having laws, for example, against speeding. ${ }^{127}$ The point of such laws, surely, is not to prevent people from being in a certain place at a certain time. Rather, they exist to ensure that people can stop their cars so as to avoid accidents, keep control of their cars, and so on. B's argument against $A$ is incoherent because

125 For the following argument in more detail, see Bruce Chapman, Limited Auditors' Liability: Economic Analysis and the Theory of Tort Law, 20 Can Bus L J 180 (1992).

${ }_{128}$ Comparable arguments were made (and rejected) in Berry v Sugar Notch Borough, $191 \mathrm{~Pa} 345,43 \mathrm{~A} 240$ (1899). The example in the text is borrowed from Ernest J. Weinrib, $A$ Step Forward in Factual Causation, 38 Mod L Rev 518, 531-32 (1975).

${ }^{127}$ Neil MacCormick makes a comparable point about coherence in the context of speeding laws. See MacCormick, Coherence in Legal Justification at 236-37 (cited in note 7). 
it combines a standard of wrongdoing based on a purposeful understanding of good conduct with a causal account of the accident that takes the accident outside the ambit of risk entailed by that understanding. We can see this incoherence only if we attend to the purpose of good conduct. Thus, even the most common of tortious interactions may present a need to consider purpose. It just so happens that a case like Caparo forces a more explicit consideration of the issue than does the standard motor vehicle accident. It will often take an overtly strange argument of the kind advanced by $B$ to generate the issue in the latter kind of case. ${ }^{128}$

To say that B's causal account of the accident that injured her is outside the ambit of risk entailed by A's speeding, purposefully understood, is merely to say that while there was a cause-in-fact connection between the two, there was no sufficiently proximate relationship between A and B to ground liability. In this way B falls prey to the exclusionary force of rule $r^{*}$. Alternatively, it might be said that, while $A$ acted negligently and endangered the public at large, there was no sufficiently proximate causal connection between A's negligence and B's injury to justify selecting B out of this more general public and according her standing to sue A.

This concern for proximity between the defendant and the plaintiff, expressed as a concern for the reasoned selection of the particular plaintiff (and, possibly, others like her) out of the public at large, appears in both Caparo and Dorset Yacht. This is important for our understanding of these two cases as "like cases" in the way represented by Figure 1, because it suggests that rule $r$ (now expressed as rule $r^{*}$, and often manifesting itself as a purpose test) was already latent in Dorset Yacht despite Lord Reid's invocation of the probability rule $u$ to define the rule in the case, which, as already shown above, was expressly denied as a rule in Caparo.

To see rule $r^{*}$ operating in Dorset Yacht, we have to turn to Lord Diplock's opinion. Like Lord Reid, Lord Diplock was concerned about how to distinguish the plaintiff, whose boat was damaged, from those members of the public who, quite foreseeably,

${ }^{128}$ The argument is "strange" because it doesn't correspond to our common understanding of the purpose of speeding laws. Of course, in a society quite different from our own, it might be possible that speeding laws were intended to prevent persons from reaching a certain spot at a certain time. My point is only that there is incoherence in B's argument because it falls outside our understanding of what speeding, and therefore speeding cases, are all about. By attending to purpose, the law reinforces rather than upsets these common social understandings. The next Section suggests that this may be important for achieving certain goals through social coordination. 
also might suffer injury if the escaped juveniles returned to a life of crime. However, while Lord Reid pointed out the distinguishing fact that the damage to the plaintiff's boat was "very likely to happen" and, presumably, damage to the others, while foreseeable, was unlikely, Lord Diplock suggested that the difference went more to the quality than the quantity of risk involved. Consider, for example, the following remarks from Lord Diplock:

It is common knowledge . . . that borstal training often fails to achieve its purpose of reformation, and that trainees when they have ceased to be detained in custody revert to crime and commit tortious damage to the person and property of others. But so do criminals who have never been apprehended and criminals who have been released from custody on completion of their sentences or earlier pursuant to a statutory power to do so. The risk of sustaining damage from the tortious acts of criminals is shared by the public at large. It has never been recognized at common law as giving rise to any cause of action against anyone but the criminal himself. ${ }^{129}$

Lord Diplock suggests at this point that it would be arbitrary and, therefore, unjust to allow those who suffer damage as a result of the tortious acts of a criminal to recover for that damage simply because the criminal happened to be an escapee who had returned to a life of crime rather than someone else who had been released before being rehabilitated or, perhaps, never apprehended at all. He continues:

To give rise to a duty on the part of the custodian . . . to take reasonable care to prevent a borstal trainee from escaping . . . there should be some relationship between the custodian and the person to whom the duty is owed which exposes that person to a particular risk of damage in consequence of that escape which is different in its incidence from the general risk of damage from criminal acts of others which he shares with all members of the public. ${ }^{130}$

Further, Lord Diplock spells out the exact nature of the "particular risk of damage" to which he sees the plaintiff in Dorset Yacht exposed:

What distinguishes a borstal trainee who has escaped from one who has been duly released from custody, is his liability

129 Dorset Yacht, [1970] 2 All ER at 333-34.

130 Id at 334. 
to recapture, and the distinctive added risk which is a reasonably foreseeable consequence of a failure to exercise due care in preventing him from escaping is the likelihood that in order to elude pursuit immediately on the discovery of his absence the escaping trainee may steal or appropriate and damage property which is situated in the vicinity of the place of detention from which he has escaped. ${ }^{131}$

These comments make clear that Lord Diplock has singled out people like the plaintiff in Dorset Yacht for special consideration, not because they may be subject to a higher degree of the same risk faced by other members of the public (Lord Reid's view), but rather because a "distinctive added risk" (arising out of what escapees do to avoid recapture) puts them in a different and more particular relationship with the defendant.

Again, just as for Caparo and the speeding case, to get a sense of what circumstances properly lie within the ambit of this "distinctive added risk," one might want to consider what we normally understand to be the special purpose of close supervision of criminal detainees who are on a training excursion to an island. What is the role of the particular supervisors involved? How would we describe their job? Surely answers to these questions will help, just as our earlier examination of the point of speeding laws helped to understand what it is to do such a job badly and, therefore, what sorts of consequences should properly fall within the ambit of risk imposed by doing the job negligently. Here, it seems that the answer, now arrived at through a particular purpose test, but no different from the one arrived at in the course of Lord Diplock's concern for "distinctive added risk," is that the job of such supervisors is to prevent escape. It is not, for example, the rehabilitation (or even the incapacitation) of the detainee so that he never again returns to a life of crime. That, most likely, would be the job of others. Thus, the added risk of doing such a supervisory job negligently is just that the juveniles might do foreseeable damage in the course of their escape. And because the general public does not face this special sort of risk unless they live in the vicinity of the escape, they have no standing to sue the defendant.

We can now see that legal feature $r$, or $r^{*}$, while highlighted as a rule in Caparo, is already latent as a legal feature in Dorset Yacht. This, together with their common concern for foreseeability (albeit interpreted differently under the aspect of a different rule), 
allows us to see Caparo and Dorset Yacht as "like cases" in the way represented by Figure 1 .

However, no explicit mention has yet been made of the role played by legal feature $r$ in case B, Wagon Mound. Still, enough has been said to allow us very briefly to suggest how the argument must go. While Wagon Mound emphasizes legal feature $t$ as the governing rule in the case, and determinative for the choice of legal state $L_{3}$, we should expect to find traces of legal feature $r$ if this case is to form part of the cycle of like cases described by the matrix. And, indeed, we do. In his opinion, Viscount Simonds uses a very effective example to show what is odd about the directness rule, which the law lords ultimately reject as bad law. He says:

Their Lordships have already observed that to hold B liable for consequences however unforeseeable of a careless act if, but only if, he is at the same time liable for some other damage however trivial, appears to be neither logical nor just. This becomes more clear if it is supposed that similar unforeseeable damage is suffered by $\mathrm{A}$ and $\mathrm{C}$ but other foreseeable damage, for which $B$ is liable, by $A$ only. A system of law which would hold $\mathrm{B}$ liable to $\mathrm{A}$ but not to $\mathrm{C}$ for the similar damage suffered by each of them could not easily be defended. ${ }^{132}$

This example, and the potential injustice it illustrates, turns on the importance of treating plaintiffs in the same proximate relation with the defendant in the same way (and, presumably, plaintiffs in a different and less proximate relation differently, the point made in Dorset Yacht). Thus, legal feature $r$ is also present in Wagon Mound, although not yet raised to the status of the case's defining rule.

\section{E. Synopsis}

This example of the process of constructing a set of like cases like those featured in the Figure 1 matrix has admittedly been long and somewhat complicated. This is in part because the process illustrated is an essentially circuitous one. There is not here the easy linearity ${ }^{133}$ and single-mindedness of maximization, constantly aimed at one external goal, nor the facile resort to skepticism,

132 Wagon Mound, [1961] App Cas at 425.

${ }^{133}$ Compare Raz, $72 \mathrm{BU} \mathrm{L}$ Rev at 277 (cited in note 7):

[P]hilosophers use "coherent" to mean something like "mutually supporting." Two be-

liefs cohere if each makes belief in the other more reasonable than its rejection. . . . 
which sees in the apparent diversity of reasons only the irrationality of fundamental contradiction. Also, the process of exemplification necessarily involves saying something about the presence and absence of each of four different legal features in four different legal cases, and why the different cases, appearing in the order that they do, have raised some of these features to the status of legal rules, or defining features, for four different legal states.

Given the length and complexity of the discussion, it is probably worthwhile to highlight some essential points. First, enough has been said, I hope, to show that four leading cases in a core area of the law can be rationalized as correctly decided "like cases" despite the fact that there is no one legal feature that is common to, or rationalizes, them all. Indeed, any attempt within a case to rationalize them all with a rule appears doomed to be upset by another case. Yet the cases appear to form a coherent whole, that is, they all attempt to formulate some understanding of a common project. The judges' opinions in the different cases point back and forth at each other for guidance even as they deny each other's attempt to formulate a final rule for all. And, of course, there will be discussion of all of these cases, as cases correctly decided despite the diversity of legal rules offered to rationalize them, in any text devoted to a coherent understanding of that one thing we call tort law.

Second, and this point is related to the first, there is little evidence in the cases that the judges view tort law as systematically setting out to achieve something, at least where that something takes the form of a goal or endpoint beyond the cases. Rather, the concern for precedent, coherence, and formal justice suggests that the cases are turned inward on themselves. At most, the cases indicate the arbitrariness and injustice of allowing a given plaintiff to collect from the defendant where other possible plaintiffs have not been allowed to recover, unless some distinction (for example, distinctive risk, or higher probability) is given. Thus, the cases articulate rules pointing only to very particular distinctions between plaintiffs and defendants and the special differences in the nature of the relationships that connect them. The rules do not attempt to stand apart from the particular distinctions raised by the cases themselves, nor do they try to rationalize all the cases from some external or Olympian point of view. At most, the only obligation the judges feel in articulating an overall rule for their particular

[This idea] recognizes a relation of justification which is not linear and asymmetrical, but is circular and symmetrical. 
judgments is to point to some new distinction at the margin of previously decided like cases; the inframarginal rule in these cases remains largely unanalyzed. Moreover, there is plenty of evidence that the judges have more confidence in the particular judgments they make than in their ability to announce a general rule that properly justifies or rationalizes, even at the margin, their judgment. For many of these judges, in other words, the particular is self-consciously prior to the general.

Third, whatever the judges themselves might say or believe about their reasons or rules in these cases, there is some evidence that their behavior is hard to rationalize as maximization. This sometimes manifests itself in a tendency to cycle; for example, although Donoghue ostensibly rejected the privity rule $r$, Caparo's general concern for proximity was not far removed, and closer still was the more particular concern voiced there for attending to the special purpose of the auditing contract linking the defendant with some third party. ${ }^{134}$

At other times, the non-maximizing aspect of case-by-case adjudication shows itself as path or partition dependence, or as a violation of WARP. Thus, the conjunction of cases A, B, and C (Donoghue, Wagon Mound, and Dorset), in the order in which they actually appeared historically, naturally raises the issue of foreseeability as probability. It is small wonder, really, that foreseeability, interpreted by Lord Reid in Dorset Yacht as the rule $u$ of higher probability, should ultimately surface out of a sequence of cases that had first alluded to relative probability as unhelpful but not wrong (Polemis, Donoghue) and then elevated it to the status of an evidentiary aid for applying the defining rule of the case (Wagon Mound).

However, a different historical sequence of the cases, or a different partition of them, would likely have presented a range of quite different comparisons and, therefore, a quite different set of issues to be decided. For example, had the cases appeared in the order C, D, and A (Dorset Yacht, Caparo, and Donoghue), they might have highlighted issues in a different way that discounted foreseeability as probability even though that legal feature, $u$, would be as much available for selection as the overall rationalization of the cases as it was in the previous sequence. Specifically, one would expect that had Caparo followed Dorset Yacht, it would have had the same effect on legal feature $u$ as it did in fact: Caparo

134 See the discussion in note 124 . 
simply buries legal feature $u$ as a possible rationalization of the cases (at least until its next moment in the cycle). According to Caparo, attending to the higher probability of the plaintiff's injury is not just unhelpful (its characterization under Polemis and Donoghue); it is actually wrong. What counts instead is the special relationship of proximity between the parties. But Donoghue would now effectively point to the inadequacy of too narrow a relational account of proximity and would broaden the rule to rule $s$, or foreseeability (plus directness). After this sequence, therefore, and in stark contrast to the result of the original order, foreseeability has little or nothing to do with higher probability. The endpoints of the decision sequences, at least as they are articulated by the rules, have effectively been determined by the order of the decision sequences.

Yet, the decisions in both sequences have effectively been exercised over the same set of possible rules (or rationalizations) as alternatives for choice. Inspecting the Figure 1 matrix, the decisions seem to be parts of the same coherent set of like cases, whatever the rules might say. This is just what it means for a set of rationalizable like cases to be path or partition dependent. These sets of cases may not be rational according to the conventions of rational social choice theory, but it is less obvious that this apparent irrationality provides any basis for judging such cases unreasonable.

\section{Rational Adjudication and Incidental Advantage: The EXAmPLe of Economic EfFiciency}

\section{A. Incidental Advantage and Social Coordination}

The last two Sections have shown that judicial law making moves from one like case to another according to different judgments of what is similar between cases. They have also demonstrated that different subsets of the overall set of like cases (reflecting, perhaps, different adjudicative sequences) highlight different legal features of the most recently chosen legal state as the organizing rule for the like cases leading up to that legal state. Nevertheless, despite this apparent diversity of reasons and rules, the private law may well be up to "something" very particular, and this would be the same something at the end of any adjudicative sequence as at the beginning, regardless of where that adjudicative sequence began.

There is, therefore, a symmetry in the different legal states that are the objects of pair-wise choice in the adjudicative se- 
quence described in Figure 1. Each legal state, rather than being chosen as a preferred legal state, is simply a further equally valid manifestation of the one legal project that is the (indefinable) focus of this overall set of like cases. ${ }^{135}$ Each legal state represents another overlapping characterization of the same project identified in the first, or precedential, legal decision. It is in this sense that it is often said that the common law "works itself pure" in the cases. ${ }^{136}$

But why should we carry on working out the different overlapping meanings or characterizations of some early legal choice? Why, in other words, carry on doing the same thing, particularly if there are better things to do if only we would focus our rational faculties on improving our choices rather than grouping "like cases?" Of course, there is some normative attraction to being consistent in this way. After all, treating like cases alike is a virtue, and one that would be lost, at least once, were we to reform and do things differently henceforth. But that cannot be the whole explanation, or even, perhaps, a large part of it. ${ }^{\mathbf{1 3 7}}$ Deductive reasoning, and certainly deductive reasoning that holds out the promise of allocating legal entitlements to achieve some good, like maximizing wealth, would also treat like cases alike, only this time defining the criteria of likeness under some universal premise. So the advantages of formal justice over deduction cannot be found in what formal justice delivers so self-consciously, namely, the like treatment of more cases of the same kind.

There may, however, be some advantage in what the formal justice of like cases delivers in an unself-conscious way, that is, only "as the by-product of actions undertaken for other ends," as Jon Elster suggests. ${ }^{138}$ Intrinsically incidental by-products are social states that, Elster argues, "can never . . . be brought about

195 Preference, by contrast, would exemplify an asymmetric relationship, or reason for choosing, between alternative legal states: if $L_{1}$ is preferred to $L_{2}$, then $L_{2}$ cannot be preferred to $L_{\mathrm{l}}$. This property of asymmetry in preference points preferences in a particular direction toward the achievement of some targeted goal. Symmetric relations between alternatives, such as might exist in cases of indifference or, as here, in a mutually reinforcing set of "like cases," do not send us off in any particular direction at all. Consider in this light Raz's remarks on the non-linear, asymmetric nature of the coherence relation as a justification, referenced in note 133. Raz goes on to show how the idea of a circular and symmetrical justification, far from being an oddity, "is deeply rooted in our ordinary understanding of justifications." Raz, 72 BU L Rev at 277-78 (cited in note 7).

${ }_{136}$ This phrase appears in Omychund v Barker, 26 ER 15, 23 (1744).

137 For an argument to this effect, see Raz, 72 BU L Rev at 302.

158 Jon Elster, Sour Grapes 43 (Cambridge, 1983). For an interesting discussion of the relevance of this idea to rational choice theory, see Robert Sugden, Rational Choice: A Survey of Contributions from Economics and Philosophy, 101 Econ J 751, 778-82 (1991). 
intelligently or intentionally, because the very attempt to do so precludes the state one is trying to bring about."139 To put the point another way, there are things we might desire that we cannot attain by any act of instrumentally rational choice. Thus, in order to enjoy the benefits of such things, we must bring them about without having chosen them or, at least, without having chosen them too self-consciously. ${ }^{140}$

The efficiency effects of coordination may be one of the most important examples of this phenomenon. Consider the case of choosing which side of the road to drive on as one approaches a blind corner. Presumably, it does not matter at all whether one chooses to drive on the left or the right so long as the party coming in the other direction (assume it is a stranger) has made the same decision. ${ }^{141}$ This is what makes the choice a matter of convention. There is no conflict of interest between the parties in this situation; it is a pure coordination problem. But the possible result when the parties fail to coordinate on some convention is very clearly inefficient. The question is how best to avoid it.

An economist, disposed to provide instrumentally rational accounts for all social institutions, might say that there is no real puzzle here. The evidence on how we solve this trite problem of coordination is all around us. We have avoided the inefficiency of crashing at every corner by simply agreeing, in North America at least, to drive on the right. Once so agreed, moreover, there is no temptation for anyone to defect from the agreement, and no real need, therefore, for legal enforcement. As the economists would say, we are blissfully in Nash equilibrium. ${ }^{142}$ Surely, this must be one of the easiest possible cases for the efficiency theorist.

But the analysis has already gone too fast. A forward-looking efficiency theorist qua rational choice theorist, that is, someone who chooses a particular action or social institution because of the good to be achieved thereby, is not someone who really takes past agreements or promises very seriously. Promises and agreements

130 Elster, Sour Grapes at 43.

140 For an elaborate discussion of a closely related problem, the ways in which moral theories can be self-defeating, see Derek Parfit, Reasons and Persons ch 1-5 (Oxford, 1986).

${ }_{141}$ See David K. Lewis, Convention: A Philosophical Study 6 (Harvard, 1969).

${ }_{142}$ A Nash equilibrium is an outcome reflecting the strategy choices of the players in a game such that, given the strategy choices of all the other players, no player can improve her pay-off by unilaterally changing her choice. See K. Binmore and P. Dasgupta, Game Theory: A Survey, in Ken Binmore and Partha Dasgupta, eds, Economic Organizations as Games 4-5 (Blackwell, 1986); David M. Kreps, Game Theory and Economic Modelling 2836 (Oxford, 1990). 
are not to be upheld unless there is a good forward-looking reason to do so, for example, that keeping the agreement will pay off better in the long run than the alternative of breaching it (as in the economist's reputational models), ${ }^{143}$ or that defection from the agreement will be legally sanctioned (as in the legal deterrence models). ${ }^{144}$ But by assumption, neither of these forward-looking arguments can do much work here, since reputation has little effect between strangers and there is no legal enforcement. Thus, there is no more reason to abide by the particular agreement reached in the blind corner case as opposed to the alternative agreement of driving on the left. Moreover, all like-minded efficiency theorists know that this is so and, further, they all know that they all know that this is so. ${ }^{145}$ This is already enough for there to be real problems, at least in theory, when two efficiency theorists drive towards each other at the blind corner, at least if they think about it too much.

However, that is exactly the point. They will not, if they are genuinely social beings, think about it at all. Rather, they will easily circumnavigate the blind corner, just as agreed, in a perfectly non-instrumental yet rational way. Each will successfully play her part in the accepted social practice and follow the social rule, as Wittgenstein says, "blindly" and "without reasons."146 Of course, it is not quite right to say that they have no reason at all for doing what they do; rather, they do what they do because that is what "is done," and always has been done, under the social practice. In contrast, exercising too much instrumental rationality (that is, thinking too much about their social practice-about what they should do and why, and further, about whether others are thinking likewise about them) will open up so many new possibilities for action, such a rich new decision space, that any chance of coordinating on the specific option made salient by prior agreement would disappear. The result may well be inefficiency, even disaster. ${ }^{\mathbf{1 4 7}}$

\footnotetext{
${ }^{143}$ See, for example, Kreps, Game Theory and Economic Modelling at 65-72.

14t See, for example, A. Mitchell Polinsky, An Introduction to Law and Economics ch 5 (Little, Brown, 2d ed 1989) (discussing the theory of efficient breach).

${ }_{145}$ In game theory, this amounts to assuming what is termed "common knowledge" of rationality among all the players in the game. See Binmore and Dasgupta, Game Theory: $A$ Survey at 3-4 (cited in note 142).

${ }_{14}$ See Wittgenstein, Philosophical Investigations at $\S \S 211,219$ (cited in note 70). Margaret Gilbert has related this aspect of Wittgenstein's work to the economic theory of games in Rationality and Salience, 57 Phil Stud 61, 75 (1989). See also Margaret Gilbert, On Social Facts 329-36 (Routledge, 1989).

${ }^{147}$ A different example, where the failure to coordinate has less disastrous implications, involves two people trying to meef, but without any prior arrangement. Even though there
} 
It may be that the greatest contribution that the common law adjudication of like cases can make toward efficiency or, more generally, the maximization of good, is the support it provides for noninstrumentally rational coordination. Moreover, as the blind corner example suggests, it may be that the conscious pursuit of some goal through the law, such as might occur, for example, if the courts were to "mimic" the market and consciously seek to maximize wealth, actually undermines any real possibility of achieving it. ${ }^{148}$ This is because a conscious pursuit of the goal opens up for individuals (or coalitions of individuals) too many possibilities of reconsidering past choices and, therefore, insufficiently anchors the different choosers, whose choices have to be coordinated after all, in some common convention or past history. Better is the process of common law adjudication that (within limits, of course) reinforces rather than constantly reconsiders our past precedents or conventions, even if to do so is to miss, from time to time, some obvious opportunity for social improvement.

Of course, this sympathetic view of precedent is inherently conservative (it is essentially conventional after all). More commonly, having a myriad of cases that have already been decided, and which burden us with their precedential weight, is viewed as a great barrier to socially beneficial reform, restricting the range of possible new (and better) decisions that might be made. ${ }^{149}$ How-

may be several closer meeting points, that is, points that involve less walking for both, the two may do better to coordinate tacitly on some more distant and more salient point. This salience, which might reflect some prior shared experience or common character trait otherwise irrelevant to the (rational choice) problem of "meeting one's friend with least physical effort," would be lost on a pair of purely forward-looking "rational" choosers. For what is probably still the best discussion of this problem, see Thomas C. Schelling, The Strategy of Conflict 53-80, 111-18 (Harvard, 1960). A more current offering, but one that defers to Schelling's original insights, is Kreps, Game Theory at 139-54, 169-77 (cited in note 142). Kreps remarks:

[T] he salience of a particular focal point in a given situation is clearly determined by the identities of the players, their cultural experiences, and so on. I don't know whether one can build a completely adequate theory of focal points based on a model of behavior that is boundedly rational and retrospective (certainly I cannot), but I cannot see that such a theory will be satisfying without coming to grips with how one's past experiences and one's knowledge (however imperfect and inferential) of others' past experiences makes one focal point salient and others not.

Id at 153 .

${ }^{168}$ Richard Posner is the best known proponent of using the private law to "mimic" efficient (wealth-maximizing) market transactions. See generally Posner, Economic Analysis of Law (cited in note 14).

140 The conservative nature of coherence theories of law is often remarked upon; see, for example, Hurley, 10 Oxford J Legal Stud at 239 (cited in note 7). Sunstein goes so far as to suggest that such theories have a "conspicuous Burkean caste," 106 Harv L Rev at 754 (cited in note 7), and cites Edmund Burke, Reflections on the Revolution in France 348 
ever, this is to assess the law exclusively as a forward-looking rational choice instrumentalist would, and to ignore that it might be just as important (even for the achievement of the rational choice theorist's own goals) to get on with some minimally acceptable convention for coordinating human action as always to seek out some uniquely "best" one.

This is not to say that genuine disagreements as to the true meaning of our adopted conventions will not arise. Having decided case A, for example, we may need to know whether what case B proposes is really the same, or whether it is something new, which might undermine received understandings or expectations and, therefore, the benefits of coordination. Thus, there will be a need for adjudication by experts, namely, by those who have developed the judgment that comes from the long experience of working within the established convention. ${ }^{150}$ But it is unlikely that this judgment will be reducible to some rule or algorithm for generating good decisions, at least if it is thought that this rule could be easily learned by anyone in the street. That would fail to explain why there might be such disagreements about the convention in the first place. Thus, the expert adjudicators of disagreement about our conventions will be people who do, in some sense, stand apart from the average person. However, they will not have to be elected, since all they would do as adjudicators is unravel the various implications of a set of institutions that their society already has, perhaps out of pure historical accident, but certainly independent of any choice that the adjudicators themselves might have made. ${ }^{161}$ In this they are to be contrasted with social reformers, or legislators, who have the power to change a society's conventions altogether.

(Gateway, 1962). 106 Harv L Rev at 754, 768. However, this may overstate the point. Burke was a political conservative, but the social practices that identify what is the "done thing" and that, on the coordination argument advanced here, it might be the business of the law to reinforce rather than constantly reconsider, could have radical change as their political goal. On this, see Brian Langille, Political World, 3 Can J L \& Juris 139, 142-50 (July 1990) (responding to criticisms that there is legal conservatism in the Wittgensteinian view that resists a skeptical account of social practice).

${ }^{160}$ Compare the discussion in the text accompanying note 82.

162 Compare Raz, 72 BU L Rev at 313 (cited in note 7): "Coherence . . . forces one to decide in a certain way because past decisions are of a certain character. Coherence gives weight to the actual past, to the concrete history of the law." Obviously, to the extent that judges are bound by coherence with the past, or the "concrete history of the law," they are more constrained by social practices and general understanding, and less free to exercise personal choice. 
This account of the coordinating effect of social practices in general, and of private law adjudication in particular, has been recently emphasized by Russell Hardin:

In this account, efforts to find a priori normative justification for many laws and for the system of common law are often wrongheaded. What justifies them is a combination of a historicist explanation of their origin and a consideration of whether they are reasonably, not ideally, workable. ${ }^{152}$

Indeed, as argued above, there may be more to be achieved for one's ideals if one sets those ideals aside, at least as a conscious goal of rational choice.

Something of the latter theme has also been taken up by Noel Reynolds in his analysis of "law as convention." Speaking of the source of legal obligation, Reynolds remarks:

[T] he "ought" of the law has little to do with either background moral theories or threats of enforcement. All it means is that each member of a community has a legitimate expectation that others act as they ought, i.e., in accordance with the conventional rules, just because those are the rules and not because they reflect any ultimate moral truth or other reality. The same obligation obtains in instances where the rule is arbitrary from every moral perspective (e.g., driving on the left).

It is worth noting in passing that to attach the law to a theory of moral truth is to lose this advantage. For it ties the "ought" of the law back to a cognitive uncertainty, i.e., the truth about morality. And to the extent that moral truth is thought to be objective and knowable, determining the "ought" of the law is transformed back into a cognitive problem with all the residual uncertainty and ground for controversy which that entails. ${ }^{163}$

Reynolds's point is that moral truth is inadequate as a basis for social coordination because it is too controversial; we simply do not know what conduct or institutions are entailed by whatever moral truths there are. It is in this sense, therefore, that his argument in favor of following the conventions or precedents of law, whatever

${ }^{162}$ Russell Hardin, The Social Evolution of Cooperation, in Karen S. Cook and Margaret Levi, eds, Limits of Rationality 358, 376 (Chicago, 1990) (emphasis added).

${ }^{183}$ Noel B. Reynolds, Law as Convention, 2 Ratio Juris 105, 108-09 (1989) (emphasis added). 
they are, rather than moral truth, is based on a kind of epistemological failing with respect to the latter.

However, in this Article I have emphasized more the logical distinctions between the theory of rational social choice and the reasonable adjudication of like cases characteristic of judicial law making. Epistemological differences have not played a major role. Thus, it is interesting to speculate whether the advantage legal conventions enjoy as a coordinating device, compared to direct appeal to moral theories, may be given a characterization which appeals more to logic than does Reynold's focus on "cognitive uncertainty." In the next Section, I add some fuel to this speculation by providing a social-choice-theoretic interpretation of what might be problematic for social coordination if, for example, courts seek to maximize wealth too self-consciously.

\section{B. Achieving Efficiency Indirectly: The Importance of Common Social Understandings}

Certainly, some moral truths (if truths they are) seem not to provide much promise for coordination even when we know with complete certainty what actions they recommend. That, arguably, is the real lesson of so much of social choice theory, which has proved the logical incompatibility, and hence the incoherence, of certain value judgments. The famous majority voting paradox, for example, shows that in a sufficiently rich space of possible decisions, ${ }^{154}$ the method of simple majority rule, a social choice rule unique in its ability to satisfy certain choice criteria, ${ }^{155}$ can fail to coordinate its voting on any one alternative in the attainable set. Under such conditions, although a majority is making every choice, there simply is not a majority-preferred outcome. Indeed, the frustration of majoritarian preferences can go so deep as to bring about an outcome that all the voters consider inferior to some other at-

${ }^{154}$ See Amartya Sen and Prasanta K. Pattanaik, Necessary and Sufficient Conditions for Rational Choice under Majority Decision, $1 \mathrm{~J}$ Econ Theory 178 (1969), reprinted in Amartya Sen, Choice, Welfare and Measurement 134, 135-57 (Blackwell, 1982). Sen and Pattanaik focus on preference restriction rather than alternative restriction, but it seems clear that this comes to much the same thing. See Amartya Sen, The Foundations of Social Choice Theory: An Epilogue, in Jon Elster and Aanund Hylland, eds, Foundations of Social Choice Theory 213, 222 (Cambridge, 1986), discussing a distinction, suggested by Robert Goodin, between "output filters" (which limit the set of choosable options given a set of preferences) and "input filters" (which limit individual preferences given a set of choosable options). See Robert E. Goodin, Laundering Preferences, in Jon Elster and Aanund Hylland, eds, Foundations of Social Choice Theory 75, 77-81 (Cambridge, 1986).

${ }^{165}$ See generally Kenneth O. May, A Set of Independent Necessary and Sufficient Conditions for Simple Majority Decision, 20 Econometrica 680 (1952). 
tainable alternative, that is, a Pareto-inferior outcome. Suppose, for example, that each of the three preference orderings (in order of preference from top to bottom) shown below in Figure 2 were held by one-third of all the voters in a jurisdiction; then a majority could choose $y$ over $z, x$ over $y$, and $w$ over $x$, a final outcome (if previously rejected alternatives cannot be reconsidered) that everyone believes is inferior to alternative $z$.

Figure 2

Majority Rule and Pareto Inferiority

Preference Orderings:

$\begin{array}{ccc}\frac{\text { Individual A }}{x} & \frac{\text { Individual B }}{\text { Individual C }} & \frac{\text { In }}{y} \\ z & z & w \\ z & w & x \\ w & x & y\end{array}$

Of more immediate concern to legal theory, and to the economic analysis of law more particularly, is the fact that the same sort of incoherence, grounded upon the same profile of individual preferences, also plagues the conscious pursuit of Kaldor-Hicks allocative efficiency. Kaldor-Hicks efficiency, of course, is what wealth-maximizing lawyer/economists appeal to when they recommend the allocation of a legal entitlement to that party who is willing to pay the most to receive it, or the party who could compensate all the losers for the loss of an entitlement and still be better off herself. ${ }^{158}$ However, since actual compensation need not be paid, Kaldor-Hicks-efficient reallocations of goods or entitlements are only potentially Pareto efficient; in actual fact, such allocations do produce losers.

This turns out to make all the difference. When actual compensation need not be paid, a sequence of Kaldor-Hicks-efficient reallocations quite possibly can make everyone a loser, that is, produce an outcome that is Pareto-inferior to another that was attainable. Since the real promise of wealth maximization is supposed to

${ }^{156}$ For an excellent discussion of Kaldor-Hicks efficiency, as well as the other notions of efficiency used in the economic analysis of law, see Coleman, 8 Hofstra L Rev 509 (cited in note 28). 
lie in the increased welfare everyone can expect to enjoy over the long run, ${ }^{167}$ this should be a disappointing implication. It is the result, however, of paying insufficient attention to the importance of having norms of coordination that, as in the blind corner case, restrict the space of possible social decisions which can be made, and remade, on apparently rational grounds. An unthinking but still reasonable adherence to these norms can prevent the ultimate choice of inefficient outcomes in a way that a fully rational and conscious pursuit of efficiency cannot.

To see this, consider what it is that we actually know when two individuals $\mathrm{A}$ and $\mathrm{B}$ sign a Kaldor-Hicks-efficient contract. ${ }^{158}$ While obviously advantageous to them, the contract might also involve a loss of business for another individual $\mathrm{C}$ who until this point had been doing business with, let us suppose, $\mathrm{A}$, but who cannot now meet the competition, or, at least, is unwilling to at the reduced price. Alternatively, one could imagine that $\mathrm{A}$ and $\mathrm{B}$ are to be advantaged by a direct judicial transfer from $C$ of some legal entitlement because they value the entitlement more than $\mathrm{C}$ on some measure of willingness-to-pay. Let the status quo ante be social state $z$ and let the new social state that advantages $A$ and $B$ to the disadvantage of $\mathrm{C}$ be $y$. Now, once in social state $y$, suppose that $\mathrm{A}$ and $\mathrm{C}$ sign their own Kaldor-Hicks-efficient contract to their mutual advantage (or, again, imagine an analogous transfer to them of some legal entitlement previously enjoyed by B), bringing about social state $x$, which is disadvantageous to B. Finally, imagine further that, in $x, \mathrm{~B}$ and $\mathrm{C}$ sign a Kaldor-Hicks-efficient contract to their mutual advantage (or gain some legal entitlement from $\mathrm{A}$ ), which is to the disadvantage of $\mathrm{A}$, producing social state $w$ as the final outcome.

The three contracts (or changes in entitlements) that take us in sequence from $z$ to $y$, from $y$ to $x$, and from $x$ to $w$, together with the preferences the three individuals would have for each reallocation, are shown in Figure 3. Individual preference relations are indicated by the symbol $\mathrm{P}$, only here the symbol is followed by a subscript indicating the individual. Thus, for example, $y \mathrm{P}_{\mathrm{A}} z$ is read "social state $y$ is preferred by A to social state $z$." Figure 3

157 See, for example, Posner, $9 \mathrm{~J}$ Legal Stud at 248 (cited in note 28). The expectation of increased welfare explains each participant's willingness to consent to a wealth maximization scheme, and it is this willingness to consent, Posner argues, which justifies the scheme. See Posner, 8 Hofstra L Rev at 495 (cited in note 28).

188 The following argument is made more concrete with an example from the corporate takeover context in Bruce Chapman, Trust, Economic Rationality, and the Corporate Fiduciary Obligation, 43 U Toronto L J 547, 556-58, 568-71 (1993). 
also shows the individual preferences that can be determined from assuming transitivity of preference.

Figure 3

Revealed Preferences From Kaldor-Hicks Trades

Assume three Kaldor-Hicks efficient trades from $z$ to $y$, from $y$ to $x$, and from $x$ to $w$ :

Trade \#1 Trade \#2 $\underline{\text { Trade \#3 By Transitivity }}$

Individual A:

$$
y \mathrm{P}_{\mathrm{A}} z
$$

$x \mathrm{P}_{\mathrm{A}} y$

$x \mathrm{P}_{\mathrm{A}} w$

$x \mathrm{P}_{\mathrm{A}} z$

Individual B:

$$
y \mathrm{P}_{\mathrm{B}} z
$$

$y \mathrm{P}_{\mathrm{B}} x$

$w \mathrm{P}_{\mathrm{B}} x$

Individual C:

$z \mathrm{P}_{\mathrm{c}} y$

$x \mathrm{P}_{\mathrm{c}} y$

$w \mathrm{P}_{\mathrm{C}} x$

$w \mathrm{P}_{\mathrm{c}} y$

The important thing to note about these preferences is that for each and every individual the preference ranking between social state $z$, where the whole contractual sequence started, and social state $w$, where it finished, is so far undetermined. Could it be that this sequence of Kaldor-Hicks-efficient contracts has only resulted in a Pareto-inferior social state, that is, that for all individuals $\mathrm{i}, z \mathrm{P}_{\mathrm{i}} w$ ?

To see that such a result is not inconsistent with the preferences implied by the three Kaldor-Hicks-efficient trades, it is enough to introduce this possibility (that is, of $z \mathrm{P}_{\mathrm{i}} w$ for each individual) explicitly into the three rows of Figure 3. This allows for a full and consistent determination of each individual's preference ordering over all four of the social states $w, x, y$, and $z$, as shown in Figure 4 (with social states ordered by preference for each individual from top to bottom in each column). 
Figure 4

Kaldor-Hicks Transacting and Pareto Inferiority

Assume for all $\mathrm{i}, z \mathrm{P}_{\mathrm{i}} w$ :

$\begin{array}{ccc}\frac{\text { Individual A }}{x} & \frac{\text { Individual B }}{y} & \frac{\text { Individual C }}{z} \\ y & y & w \\ z & w & x \\ w & x & y\end{array}$

Given these orderings over the four social states, the three KaldorHicks-efficient contracts that take us from $z$ to $y$, from $y$ to $x$, and from $x$ to $w$, add up to a Pareto-inferior outcome, or an outcome in which every individual is worse off than when she started. ${ }^{169}$

169 One might think it impossible to distribute wealth, as measured by willingness to pay, over the three transactions (from $z$ to $y$, from $y$ to $x$, and from $x$ to $w$ ) so that everyone is made worse off than when they started. But the possibility is real, and it turns on taking the "ability to pay" constraint seriously-having "paid" for some beneficial transactions, one runs out of the wealth needed to resist the harmful transaction when it appears in the transactional sequence. Of course, one does not actually pay in Kaldor-Hicks-efficient transactions, but if willingness to pay is going to mean anything, one has to take the idea of a budget constraint seriously. In Figure 4, for example, let the willingness of -individuals $A$ and B to pay for the choice of $y$ over $z$ be represented (in dollars) as $a$ and $b$ respectively. Let $C^{*}$ represent all of C's wealth (in dollars) and, therefore, the maximum $C$ would be willing and able to pay to avoid this same transaction, the worst possible for her in this scenario. Thus, transaction $y \mathrm{Pz}$ implies that the aggregate willingness of $\mathrm{A}$ and $\mathrm{B}$ to pay for $y$ over $z$ exceeds C's willingness to pay for $z$ over $y$, or that:

(1) $a+b>C^{*}$

If, analogously, we let $A^{*}$ and $B^{*}$ represent all of the wealth of $A$ and $B$ respectively and, therefore, their maximum willingness to pay in this example, then $\left(\mathrm{A}^{*}-a\right)$ and $\left(\mathrm{B}^{*}-b\right)$ represent their maximum willingness to pay after the first transaction $y \mathrm{P} z$ has taken place. Then if we let $c$ represent C's willingness to pay for the choice of $x$ over $y$, then the subsequent transaction $x \mathrm{P} y$ implies:

(2) $c+\left(\mathrm{A}^{*}-a\right)>\left(\mathrm{B}^{*}-b\right)$

Further, the transaction $w \mathrm{P} x$ implies analogously:

(3) $\left(\mathrm{B}^{*}-b\right)+\left(\mathrm{C}^{*}-c\right) \mathrm{A}^{*}-\left[\left(\mathrm{A}^{*}-a\right)+a\right]=0$

Gathering terms on each side of these inequalities implies that

(4) $\mathrm{A}^{*}+b>0$

which shows that the transactional cycle can occur, given these preferences, if either $B$ is willing to pay some positive amount to move out of the initial social state $z$ or $\mathrm{A}$ is willing to pay some such positive amount to move out of $z$ and/or $y$. Of course, this suggests that $A$ and $B$ are slightly myopic (in that the choice sequence they undertake will end up making them all worse off), but that is consistent with the usual demonstration of the majority voting paradox, and is certainly implied by the majoritarian route to the Pareto-inferior outcome in Figure 2. 
What is striking about the problematic preference profile shown in Figure 4, a profile problematic for Kaldor-Hicks-efficient reallocations, is the fact that this is the same preference profile featured in Figure 2. Moreover, it can be easily proved that the Figure 2 preference profile must be present somewhere in the population of voters if the majority voting paradox is to be produced. ${ }^{160}$ Thus, any suggestion that there is a (political) failure to coordinate voting in the latter situation can be matched by an equally valid claim that the former situation exhibits a (marketlike) failure to coordinate the process of efficient contracting. Moreover, any attempt to "mimic" these contracts with judicially imposed Kaldor-Hicks-efficient transfers of legal entitlements, such as is characteristic of much economic analysis of law, should fall prey to the same problem. Kaldor-Hicks-efficient contracting, when it is taken to a sufficiently rich space of possible decisions, can produce the same inefficiency, over the same profile of individual preferences, as majority voting.

As the blind-corner example showed, however, norms of coordination work to restrict the exercise of rational choice by restricting the space of possible (new) decisions. This is what allows two reasonable persons to successfully get around the blind corner; they get around without thinking too much (again) about what else they might rationally do. Since the difficulties in both the voting paradox and the Kaldor-Hicks contractual sequence arise from the same overly rich space of possible decisions, some restriction on the space of possible decisions or, equivalently, some restriction on the admissibility of individual preferences into a given decision space, is likely to be required.

The need for such preference restrictions has been explicitly recognized at a theoretical level in the economic literature on social choice dealing with majority voting. ${ }^{161}$ Specifically, the argument is that the majority voting paradox can be avoided if individual preferences are "single peaked," that is, if all individuals agree that

${ }^{160}$ This expresses the point somewhat loosely. What can easily be proved is that, assuming strict individual preferences only (no indifference), the profile of individual preference orderings over the three alternatives $x, y$, and $z$, represented in Figure 2, must be present somewhere in the voting population if a majority voting paradox is to occur. For an easy exposition, see Robert Sugden, The Political Economy of Public Choice 157-58 (1981). For a closely related argument and formal exposition, see Sen and Pattanaik, Necessary and Sufficient Conditions at 178-201 (cited in note 154).

${ }^{161}$ See id. For an interpretation of the coordinating effects of these restrictions on individual preferences in terms of the age-old debate on the legal enforcement of morality (the Hart-Devlin debate), see Bruce Chapman, Law, Morality, and the Logic of Choice: An Economist's View, 29 U Toronto L J 114 (1979). 
any set of three of the alternatives for choice can be arranged along some continuum of judgment such that one of the alternatives is at least of intermediate value on that continuum, that is, is a "not worst" alternative. In the problematic profile of preferences represented in Figures 2 and 4, this form of preference restriction ${ }^{162}$ is not satisfied for the set of alternatives $(x, y, z)$. That is, there is no way of arranging these alternatives in any order (as if along a judgment continuum) such that the intermediate alternative on that continuum will not be the worst of the three for someone. This suggests that there is not a judgment continuum accepted by everyone as the relevant one for these alternatives. Hence, the manifest problems of social choice generated by this particular preference profile.

Could it be that the great genius of common law adjudication is that it recognizes the need for such individual preference restrictions? Perhaps the common law seeks to avoid the problems of social coordination, exemplified by majority voting paradoxes and Kaldor-Hicks contracting cycles, by constantly reinforcing received understandings about the relevant judgment continua for different sets of social alternatives. Without such reinforcement, the argument might go, the danger of constant reconsideration of the rationality of social choice remains, with only confusion and chaos as the result.

This danger may be particularly acute in a pluralist society, whatever the advantages living in such a society might otherwise bring. Consider, for example, these remarks by Joseph Raz:

$[\mathrm{M}]$ oral pluralism leads to the permanence of conflict and to occasions in which social policies are adopted by choice rather than reason. In these instances, it is important to adhere to a policy once it is chosen. . . . [A]dhering to the chosen solution is necessary for it to work in all cases where its benefits depend on social coordination. . . . Where a person can decide one way one day and the opposite way the following day (in matters in which there is no overriding reason to decide one way or the other), an institution may well be thrown into considerable confusion and chaos if it is allowed to do so. ${ }^{183}$

${ }^{362}$ Because only the pattern of preferences across individuals is restricted, but particular preferences are not (any preference between any pair of alternatives is permissible), a better term is "value restriction." The latter is the term used by Sen and Pattanaik, Necessary and Sufficient Conditions (cited in note 154).

${ }^{163} \mathrm{Raz}, 72$ BU L Rev at 313 (cited in note 7). 
Raz is careful to add that he does not mean that society "should never change, only that it should not be changed too frequently." ${ }^{164}$ Thus, we see here a social coordination rationale for the gradual incrementalism we observe in the development of a coherent set of like cases within the common law. This cannot be its conscious goal, of course, but it could still be a large part of its justification. The irony is that, applied to efficiency, this insight has still to be appreciated in the economic analysis of law. By rationally seeking to maximize wealth in every legal choice, the economic analyst of law endangers the goal she seeks most to achieve, namely, a world in which we are all better off or, at least, one which we all prefer.

\section{ConCLUSION}

Legal theory and economic theory can both claim to be fully legitimate studies of rational decision making. However, it is striking how little intellectual exchange has taken place between the economic theory of rational social choice and the modelling of legal reasoning. This, by itself, suggests that the term "rational" has quite different meanings in law and in economics, despite the close collaboration between these subjects in so many other respects in recent years.

This Article's primary purpose has been to demonstrate that lawyers and economists do, in fact, understand the term "rational" differently. What is reasonable or coherent in law is both more and less demanding than what is required by consistency in rational choice. Coherence is more demanding because it emphasizes the constant reinforcement of a historically conditioned project identi-

${ }^{164}$ Id at $313 \mathrm{n} 72$. Note that in this same paper Raz comes close to advocating the achievement of moral goods as an incidental by-product rather than as a consequence of direct and maximizing pursuit. For example, he states:

Social pluralism, that is, the existence of a plurality of inconsistent views on moral, religious, social, and political issues in democratic (and in many other) societies, is likely to be refiected in a society's law. That is, it is likely to lead to legal rules and principles being in force reflecting the different outlooks of the people who fashioned them. This may lead the courts (and legislatures) to a dilemma. A court may be faced with a case in which it can, in principle, embrace a ruling which is morally best. Because the law on related matters was developed by people with misguided ideas, however, embracing the morally best rule may lead to bad eonsequences. That is, it may lead to the existence of different rules pushing in different directions, encouraging conflicting social and economic conditions. Thus, the actual consequences of embracing the (otherwise) morally best ruling may be far from ideal. Indeed, there may be a less than ideal alternative ruling which, if adopted, would have better social and economic consequences for as long as the other misguided rules remain in force.

Id at 311-12. 
fied (quite contingently perhaps) by some prior precedent. It is less demanding because such coherence cannot even guarantee the seemingly weak rational choice requirements of dominance and internal consistency. The reasonable, therefore, falls short of the rational in some respects, although not so far as to provide any grounds for the skeptical.

This Article has also suggested that the common law method of adjudication might, quite incidentally, achieve certain goals even if it is not self-consciously designed or structured to do so. Indeed, it may better achieve those purposes precisely because it does not seek to do so. This last point was illustrated by showing how the rationally self-conscious pursuit of wealth maximization could be self-defeating, at least if wealth were thought to have much to do with welfare.

My claim that neither adjudication nor legal reasoning is particularly well-structured to maximize wealth will surprise only a few. That neither are particularly well-structured to achieve much good at all, at least self-consciously, will, I suspect, surprise many more; but the reason for each of these apparent failings is the same. Even this much may still leave the legal skeptic unsurprised, since she may well have thought all along that the law was good for nothing. However, my. claim that adjudication and legal reasoning are coherent despite all this will strike many as irrational in itself, if not totally absurd.

In the final analysis, this Article has provided only the rough beginnings of an argument that this last claim is not only not absurd, but actually quite reasonable. Indeed, it follows from this Article's claims for reasonableness that any reasonable claim it makes must have this tentative nature. For the claims of this Article (of this I am certain) must also be defeasible, much like the rules announced by judges as rationalizations for the cases. They await, openly, non-defensively, and in the non-dogmatic way which is, I hope, also characteristic of law's reasonableness, ${ }^{165}$ subsequent developments (and outright corrections) in a new joint literature on rational choice and legal reasoning.

But an author can also take some positive comfort in the characterization of his or her claims as defeasible. For, as its origin in property law suggests, a defeasible claim, although subject to de-

${ }^{185}$ Richard Rorty has developed this characterization of the rational person as someone willing to listen and be open to the views of others in Science as Solidarity, in John S. Nelson, Allan Megill, and Donald N. McCloskey, eds, The Rhetoric of the Human Sciences 38 (Wisconsin, 1987). 
feat in the face of certain contingencies, nevertheless survives intact if no such contingencies arise. That is the great advantage of a reasonable claim over a skeptical one, at least when each is used in a self-referential way. ${ }^{166}$ While both may deny for themselves the full vigor of the rational, the reasonable claim, unlike the skeptical one, is not caught by its own dissolving power in a self-refuting way.

${ }^{166}$ See J. M. Finnis, Skepticism, Self-Refutation, and the Good of Truth, in P.M.S. Hacker and Joseph Raz, eds, Law, Morality and Society 247 (Oxford, 1977). 